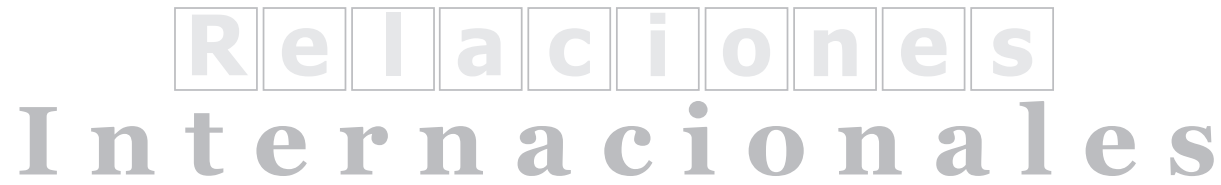





\title{
Nueve lecciones (preliminares) \\ de las revueltas árabes a los movimientos sociales*
}

\section{Nine (preliminary) lessons learnt from the Arab revolts to the Social movements}

\author{
Víctor de Currea-Lugo ${ }^{* *}$
}

Recibido: 03/02/2014

Aprobado: 22/03/2014

Disponible en línea: 01/07/2014

\section{Resumen}

Estudiar las revueltas árabes es estudiar un fenómeno en curso y por tanto, es difícil adelantar conclusiones. Al margen de esta realidad, tenemos la obligación académica de mirar las revueltas, de acercarnos a ellas y de beber de sus aguas. En esta época de crisis de referentes sobre cómo hacer política desde la sociedad, las revueltas árabes ya dan algunas enseñanzas preliminares. Más que enseñanzas en el sentido de fórmulas mágicas, son dilemas y/o tensiones políticas útiles y generosas en preguntas, tales como: la construcción de modelos políticos, su relación con lo étnico, lo religioso y lo tribal, los retos de la estigmatización y la definición de medios para la acción política.

\section{Palabras claves:}

revueltas árabes; movimientos sociales; Oriente Medio; sociedad civil

\section{Abstract}

Studying the Arab revolts is to study an ongoing process, and therefore it has limits which prevent us from formulating final conclusions. However, there is an academic obligation to study this process. In these times of lack of references about how to work politically among societies, the Arab uprising may offer some preliminary lessons. These lessons are not magical formulas, but dilemmas and political tensions, useful and full of questions, such as: how to construct political models, its relationship with ethnical, religious and tribal agendas, the challenges of stigmatization, and the definition of methods and means for political action.

\section{Keywords:}

Arab Revolts; social movements; Middle East; civil society

doi:10.11144/Javeriana.PAPO19-2.nlra

* Artículo de Reflexión.

** Profesor de Relaciones Internacionales de la Pontificia Universidad Javeriana y colaborador permanente del periódico El Espectador. Su último libro es: Las revueltas árabes: notas de viaje, Le Monde Diplomatique, Bogotá, 2011. Correo electrónico: vdecurrea@javeriana.edu.co 
564 Víctor de Currea-Lugo

\section{Cómo citar este artículo:}

Currea-Lugo, V. (2014). Nueve lecciones

(preliminares) de las revueltas árabes a los movimientos sociales. Papel Político, 19(2).

pp. 563-6oo. http://dx.doi.org/10.11144/

Javeriana.PAPO19-2.nlra 


\section{Advertencia para 'occidentales'}

En el mundo cristiano Jesús es profeta (y Dios al mismo tiempo) y actúa como intermediario en la relación del creyente con Dios, por eso a sus seguidores se les llama cristianos. En el mundo musulmán no existe la idea de intermediación ante Alá (palabra árabe que significa Dios) por parte de su profeta Mahoma (o Mohamed, si se prefiere). Por tanto, hablar de 'mahometanos' es el resultado erróneo de querer traducir lo musulmán en clave cristiana para poder entenderlo. Pero en esa traducción simplista se sacrifica de paso la esencia misma del Islam. Lo mismo pasa con las revueltas. Por ejemplo, lo religioso trata de ser presentado como una novedad, como si lo musulmán fuera algo externo que 'atacara' al mundo árabe y no una cotidianidad, que en algunos casos data del siglo VII.

Para entender las revueltas, corrimos a explicarlas mecánicamente a través de nuestra propia tradición, inventando: vanguardias que no existen como tales (una especie de Lenin-Mahoma dirigiendo las masas); aliados de los rebeldes que dominarían por completo sus agendas y sus voluntades políticas (la CIA, Al Qaeda); métodos de movilización que remplazan a las masas movilizadas y que adquieren vida propia y hasta finalidad política (Facebook, Twitter); y agendas religiosas preexistentes a dictadores y a reyes ${ }^{1}$.

Lo mismo ha sucedido con la definición de las revueltas como 'la primavera árabe', con el fin de hacerla comestible a los paladares occidentales. Para algunos, inundados por la tendencia a llamar 'revolución' a toda protesta callejera con cierto respaldo², se trataría de la 'revolución árabe'. Para otros se trata de la 'primavera' árabe, haciendo equivalentes tales sucesos con las revueltas europeas de mediados del siglo XIX ${ }^{3}$, o comparables con $1989^{4}$.

Así, estereotipos, prejuicios e ideas preconcebidas aparecen en la escena cada vez que se intenta explicar una nueva realidad política y las revueltas árabes no son la excepción. Además de reducirlas a cosas conocidas, se les redefine según lo que queremos que sean, descuidando lo que en realidad pueden ser.

\section{La noción de movimientos sociales}

Desde la teoría es difícil contar con una definición consensuada sobre movimientos sociales. Según Pasquino, se puede ver en dos dimensiones: quienes ven en los movimientos sociales una 'irrupción (irracional) de las masas en la escena política', y quienes ven 'una modalidad de acción social'. Pasquino se atreve a definirlos como "intentos fundados en un

\footnotetext{
${ }_{1}^{1}$ Para profundizar en esos debates, ver De Currea-Lugo (2012, invierno).

2 En 2003 se habló de la 'Revolución Rosa' en Georgia; en Ucrania de la 'Revolución Naranja' en 2004; y en Kirguistán en 2005, se habló de la 'Revolución de los Tulipanes'.

${ }^{3}$ Es el caso de Eric Hobsbawn: "It reminds me of 1848..." Entrevista con Andrew Whitehead, BBC News Magazine, Diciembre 23 de 2011

4 Para una crítica a estas lecturas, ver: Haroon Moghul: "This isn't 1989", Institute for Social Policy and Understanding, marzo 18 de 2011. Disponible en: http://ispu.org/GetArticles/48/2062/Publications.aspx
} 
conjunto de valores compartidos para redefinir las formas de la acción social e influir en sus consecuencias" (Pasquino, 1983, p. 1015), pero dicha definición no deja de ser imprecisa, como muchas otras, a pesar del diálogo creciente entre movimientos sociales y académicos.

Según Sidney Tarrow, los movimientos sociales son "desafíos colectivos planteados por personas que comparten objetivos comunes y solidaridad, en una interacción mantenida con las élites, los oponentes y las autoridades" (Tarrow, 2004, p. 24). Son desafíos colectivos, en tanto hacen uso de sistemas de protesta per se contestatarios, tomando como medio el ejercicio de la acción directa ante una inconformidad generalizada, proyectados a influir en el sistema político, y mediados - por concebirse a partir de orientaciones concretas- por múltiples variables propias de un contexto percibido como subóptimo. De este modo, la acción colectiva expresada en los movimientos sociales surge en un momento político propicio para la intervención de agentes sociales que normalmente se encuentran excluidos de los sistemas institucionales de participación, obedeciendo a una diversidad de orientaciones de muchas naturalezas, ya sean materiales o ideológicas.

Según Alain Touraine, el movimiento social: a) se define a sí mismo -principio de identidad-; b) el conflicto hace surgir al adversario -principio de oposición-; y c) los adversarios mantienen su disputa en un 'sistema de acción histórica' -principio de totalidad- (Pasquino, 1983, p. 1017).

Las teorías se mueven entre una sobrevaloración de la noción de movimientos sociales hasta su categorización como simples indicadores de 'disfunción social', pasando por su reducción a fenómenos psicológicos colectivos. Para Neil Smelser lo determinante es el peso de las creencias; para Touraine lo determinante parecieran ser las tensiones de clase y para Francesco Alberoni la tensión entre viejas y nuevas solidaridades (Pasquino, 1983, pp. 1016-1019). Sería la acción misma la que determina al colectivo movilizado y la membresía individual al colectivo dependería más de elementos subjetivos que de criterios objetivos (Fligstein y McAdam, 2011, p. 3)

A pesar de lo avanzado en marcos teóricos sobre la noción de movimientos sociales, sigue abierto el debate sobre la valoración que cada miembro del movimiento social hace de la acción de otro (tensión entre una acción y su interpretación), de los límites (difusos) de lo que llamamos movimiento social, de la estructura de gobierno en el espacio público (que no necesariamente coincide con la estructura de las instituciones que convergen en el movimiento social) y del impacto de los actores sociales en la construcción de la sociedad misma, entre otros temas (Fligstein y McAdam, 2011, pp. 4-7).

La acción movilizadora es caracterizada por Fligstein y McAdam en tres fases: desorganizada o emergente; organizada estable y cambiante; y abierta a la transformación (Fligstein y McAdam, 2011, p. 11). En este sentido, un movimiento social también enfrenta una transformación interna permanente, desafíos continuos que determinan su propia dinámica. 
En el caso del mundo árabe, las revueltas populares "ponen fin a una anomalía histórica en el mundo árabe: la marginación de la ciudadanía en el proceso de construcción nacional” (Alvarez-Ossorio, 2013, p. 18), máxime si reconocemos que la configuración actual de Estados-nación de Oriente Medio y del Norte de África es fruto de un reciente, violento y artificial proceso, impuesto por el poder europeo a finales de la Primera Guerra Mundial (Mansfield, 2003).

Algunos autores prefieren el término de sociedad civil para referirse a la acción social colectiva del mundo árabe. Si bien es cierto que hay suficiente evidencia para hablar de una sociedad civil árabe, hay también una marcada reticencia a su uso por parte de intelectuales árabes por su sesgo ‘occidental' (Alvarez-Ossorio, 2013, pp. 21-44). A esto se suma la tendencia a identificar la noción de sociedad civil con una perspectiva neoliberal, en la cual aquella no es simplemente una expresión autónoma frente al Estado sino que se trata de un juego conceptual que legitima la separación entre este y el mercado.

Es necesario incluir que el grado de no organización de la sociedad árabe presente en las manifestaciones de los últimos años, no muestra un proceso de institucionalización tal, por lo que hace más prudente hablar de movimientos sociales que de sociedad civil.

\section{Lección 1. El paso de la indignación a la protesta}

La toma de la llamada 'calle árabe' por miles de personas no fue un acto espontáneo, fue el fruto de un largo proceso y del malestar social por las condiciones políticas y sociales. Organizaciones de diferente naturaleza surgieron desde los años ochenta "cuyo número se estima hoy en cerca de ciento veinticinco mil [...] cuando en 1960 no alcanzaban las diez mil” (Alvarez-Ossorio y Gutierrez De Terán, 2011, pp. 14-15).

Nadie fuera del mundo árabe predijo los alcances de las revueltas: no hubo fe en los movimientos sociales ni en su capacidad, de hecho unos de los más sorprendidos fueron los mismos manifestantes. Aunque había un antecedente de protestas limitadas en su capacidad de movilización, las marchas ahora fueron una renuncia al digamos, 'foquismo político’ para dar pie a una expresión multitudinaria.

En Egipto solo entre 2004 y 2010 las protestas laborales fueron más de 3.000, (Lampridi-Kemou, 2011, p. 63). Allí, en enero de 2011 los egipcios siguieron el ejemplo de su vecino Túnez, que en cuatro semanas había sacado del poder a un presidente que había estado en el poder durante 24 años. En Túnez, el suicidio del joven Mohamed Bouazizi fue el detonante de la protesta. La identificación de la juventud tunecina con el drama personal de Mohamed Bouazizi fue fundamental para garantizar la movilización social que ya tenía justificación en los altos niveles de desempleo (Alba Rico, 2011).

En Siria, el conflicto actual tuvo varios momentos previos de alta relevancia: el “Manifiesto de los 99" (de 2000) y la "Declaración de Damasco" (de 2005). Ambos documentos pedían libertad y reformas democráticas, pero fueron respondidos con 
detenciones, torturas y persecución (Alvarez-Ossorio, 2009, pp. 182-184). Sin embargo, el levantamiento de 2011 no provino de dichas declaraciones ni de los llamados en Facebook a los 'días de la ira'. Fue el ataque de la policía contra unos jóvenes grafiteros en la ciudad sureña de Deera, la que produjo la explosión social. Las torturas hechas a los jóvenes y los disparos contra sus familiares terminaron en un levantamiento social que luego se extendió por todo el país 5 .

La gran enseñanza radica en pasar de la indignación que se escuchaba en las calles a la acción política. En la novela Taxi, el novelista egipcio Khaled Al-Khamissi ya refleja el gran descontento social en la ciudadanía egipcia (Al Khamissi, 2009). Para que esa indignación se extendiera fueron necesarias, acciones como los manifiestos ya citados contra el gobierno, pero lo más importante: la capacidad de solidaridad de la sociedad para con las víctimas, ese 'ponerse en los zapatos del otro'. Dicho proceso estuvo mediado por varios factores, entre ellos la política neoliberal y el hastío por la falta de libertades, además del concepto extenso de familia en el mundo árabe ${ }^{6}$.

Algunos sirios cuentan que, luego de los hechos de Deera (marzo de 2011), salieron a las calles a protestar contra el gobierno y que en el desarrollo de dichas protestas sintieron, casi mágicamente, que un día desapareció el miedo y según ellos, eso marcó un nuevo espíritu de lucha, una nueva convicción7.

Según Barreñada,

[...] las manifestaciones de 2011 se inscribieron así en un continuum contestatario, siendo herederas de experiencias de resistencia, protesta y organización previas, y constituyen un punto de inflexión en el proceso. Este continuum prosigue en las transiciones políticas en curso. (Barreñada, 2012, pp. 45-66)

Si bien es cierto que redes organizativas previas jugaron un papel de acumulación, las revueltas se dieron también por fuera y por encima de ellas; de hecho, hasta los Hermanos Musulmanes en Egipto estaban realmente sorprendidos con las manifestaciones y les tomó varios días posicionarse.

Lo común es el reconocimiento de la realidad de cambio y, tal vez lo más importante, el reconocimiento de la capacidad de hacerlo. La famosa frase de 'El pueblo se levanta cuando es consciente de su fuerza y pero solo será consciente de su fuerza el día en que se levante' como una fatalidad que señalaba la condena a la resignación de las masas

\footnotetext{
${ }^{5}$ Entrevistas del autor con sirios en Damasco (mayo, 2011) y en la frontera con Turquía (junio de 2012).

${ }^{6}$ Esta explicación de la lógica de la familia extensa como elemento de cohesión/identificación política fue ampliamente argumentada ante el autor por un grupo de jóvenes jordanos (Amán, mayo de 2011). ${ }^{7}$ Entrevistas del autor con varios jóvenes sirios en el mercado de Damasco (mayo, 2011).
} 
árabes, no se cumplió más. El éxito de las revueltas ha sido que el pueblo del mundo árabe fue capaz de hacer caer gobiernos en Túnez, Egipto, Libia y Yemen.

Si bien en todos los países involucrados en algún momento, las banderas llamaban a las reformas, rápidamente ganaron las banderas del cambio de gobierno y demostraron en los casos de Túnez, Egipto y Libia que ese cambio sí era posible. Encarnaron un real 'sí podemos' de los movimientos sociales, que se materializó en cambios, no solo del gobernante de turno, sino de la Constitución (Túnez), de la dinámica de las organizaciones políticas (Egipto) y de la naciente institucionalidad estatal (Libia).

\section{Lección 2. La capacidad de las masas para determinar la agenda política}

La construcción de agendas sociales es un proceso complejo. En el caso de las revueltas árabes, hay dos preocupaciones que se materializan en dos ejes de construcción de la agenda social: frente a lo neoliberal, la protesta ha sido más reactiva (en el sentido de consecuencia directa de una política económica determinada sin necesariamente formular una alternativa); y frente a la democracia, la protesta ha sido, además de reactiva, propositiva (en el sentido de rechazar el autoritarismo proponiendo ciertos modelos alternativos).

La primera agenda aglutina más fácil a las masas, genera mayor consenso y una respuesta más 'simple’: el Estado social, ese que prometió el capitalismo bismarckiano y keynesiano. Las reivindicaciones de los movimientos sociales árabes por justicia social tampoco eran nuevas en la región: en Egipto 'las revueltas del Hambre' de 1977, lograron vencer en solo tres días al gobierno de Anwar El-Sadat y a su política neoliberal de recorte de subsidios, obligándolo a restablecer las ayudas sociales (Pommier, 2009, pp. 75-76). A medida que ha avanzado en los últimos treinta años la implementación de políticas neoliberales, asimismo se ha consolidado una conciencia social en su contra.

La segunda agenda tenía en cambio, varios enemigos: la incapacidad de algunos de no ver la falta de libertades, la eficacia del sistema clientelar y lo más grave, la falta de consenso sobre hacia dónde avanzar y qué tan lejos ir; pero sí hay un punto de unidad: el rechazo al autoritarismo y la fe en la democracia como sistema alternativo. De hecho, en una encuesta realizada en doce países árabes, el 81\% de los entrevistados explicó detalladamente el tipo de democracia que querían: de acuerdo a sus necesidades (incluyendo elementos sustantivos como el pluralismo político, la protección de derechos humanos, la justicia social, etc.) (Arab Center for Research and Policy Studies, 2012).

La apuesta por el alcance en las reivindicaciones políticas, se vio matizada por el grado de violencia con que los regímenes enfrentaron las críticas: paradójicamente a mayor violencia, mayor profundidad en las demandas de los manifestantes (Bahréin, Libia, Siria, Yemen). Además de esto, la ausencia de un liderazgo único en las revueltas permitió y fortaleció la formulación de un sinnúmero de agendas, incluyendo aquellas 
que cierta izquierda tradicional desconoce, como fueron las reivindicaciones de género y de identidad cultural.

Las mujeres son quienes tienen más razones para rebelarse en el mundo árabe, no solo porque reciben menores salarios que los hombres, sino porque gozan de menos libertades y -dependiendo el país- están sujetas a la ley islámica, enfrentan prácticas como la mutilación femenina, tienen los niveles más altos de analfabetismo y desempleo (The World Bank, 2009). Es decir, sufren lo peor del arabismo, el islamismo y el africanismo (sea lo que sea esta colección de ismos).

En todos los países con revueltas, las mujeres han jugado un papel decisivo en las plazas y en las calles. Allí hay médicas cuidando de los heridos, activistas arengando desde los micrófonos, mujeres al frente de la organización de servicios básicos en las plazas, profesoras, blogueras, abogadas, madres y compañeras de víctimas; periodistas con y sin velo, incluso mujeres que, como en Libia, empuñan el fusil. Es decir la llamada 'calle árabe’ no es exclusivamente masculina.

Con diferencias en matices y velocidades, prácticamente todos los gobiernos cuestionados siguieron el mismo libreto de acercamiento a la oposición: cambios en sus gabinetes, (Egipto (Al Jazeera, 2011), Yemen), reconocimiento de las protestas, promesas de reformas constitucionales (Túnez, Siria, Egipto), promesas de creación de empleos, lucha contra la corrupción, disminución de precios y diálogo con la oposición (Túnez) (Martinez, 2011, pp. 32-39); liberación de prisioneros (Siria, Bahréin), aumento de salarios (Egipto), etc. Esas promesas no son nuevas. En 2005 según la ONU: "los gobiernos árabes anunciaron una serie de reformas destinadas a promover la libertad y el buen gobierno, la mayoría de las cuales quedaron en el plano más superficial de sus ambiciosas agendas" (UNDP, 2005). Pero no es aventurado decir que uno de los elementos que llevó al fracaso a tales cantos de sirena fue precisamente la multiplicidad de agendas, lo que evitó la cooptación de los líderes de las revueltas por parte de unas élites acorraladas.

La presión social en las calles, con una agenda heterogénea y desafiante, hizo que los gobernantes fueran los que se adaptaran a la agenda de las calles y no al revés, así la política estuvo determinada de abajo hacia arriba (Túnez y Egipto), mientras en otros casos (Libia y Siria), la negación de dicha agenda social contribuyó a la radicalización de la protesta, hasta llegar a la lucha armada.

Lo rescatable es que no hubo sometimiento a un único libreto sino que hubo una multiplicidad de agendas en las manifestaciones observadas en los últimos años, donde no hubo una única reivindicación ni el aplazamiento de unos debates so pretexto de otros más relevantes. En los debates del Foro Social Mundial realizado en Túnez en 2013, se evidenció tal ramillete de agendas sin que existiera una jerarquía en los discursos. 


\section{Lección 3. La renuncia a la vanguardia única}

El debate no es solo de múltiples agendas sino también de múltiples actores. No hay un solo actor que puede autoproclamarse líder de las revueltas ni vocero de ellas. A pesar de esto, hay una actitud casi enfermiza de demandar a los opositores unidad, partiendo del hecho de que la unidad es garantía automática de democracia, victoria, participación y un largo etcétera. Es el caso de las presiones internacionales sobre la oposición siria en este sentido.

La multiplicidad de voces preocupa a Occidente pero no a los árabes y asusta a una izquierda anquilosada en el mito de la vanguardia. Los árabes se movilizan más como sociedad que como grupos políticamente organizados y buscan mantenerse como expresiones políticas heterogéneas antes que como vanguardias. Incluso organizaciones muy 'vanguardistas', como los Hermanos Musulmanes, se han plegado a direcciones colectivas (Siria) o han explorado alianzas políticas en la transición (Egipto), pagando un precio político cuando tratan de ir en solitario (Egipto).

Hay dos experiencias revolucionarias previas en la región que se separaron un poco de la idea de vanguardia única y apostaron muy brevemente por una dirección digamos colegiada: la revolución egipcia de 1952 en la que confluyó el panarabismo árabe, los comunistas y los musulmanes organizados políticamente; y la de 1979 en Irán, donde igualmente confluyeron diversas opciones políticas; pero ambas experiencias finalmente cayeron en la lógica de una vanguardia única que desplazó a sus aliados: los Oficiales Libres de Nasser en Egipto y el Ayatolá Jomeini en Irán.

Ese rechazo a la idea del 'partido único' es en parte, el rechazo al modelo bajo el cual han estado dominados, donde un solo partido rige sus destinos (Egipto, Siria, Irak), o en contra de liderazgos personales que incluso trascienden y niegan las formaciones políticas (Mubarak, Gadafi, Saleh).

La pluralidad de voces es positiva porque corrige y confronta viejas lógicas izquierdistas que negaron por décadas a otras agendas diferentes a la lucha de clases, lógicas dentro de las cuales los jóvenes no tenían cabida (solo en cuanto obreros), ni la agenda de género (reducida a su relación con la explotación capitalista y aplazada $a d$ eternum hasta la llegada al comunismo soñado).

La cara 'negativa' se observa en la definición de prioridades en la agenda política, lo que no es solo un capricho de pocos, sino una necesidad dada por la dinámica de un contexto que no da espera. Bajo esta lógica, la inclusión nominal de varias agendas tampoco implica una inclusión real, con lo cual el riesgo de que voces heterogéneas no mayoritarias terminen sin tener un puesto político es alto. Es decir, al final no se gana en heterogeneidad pero sí se pierde en avanzar en una agenda común.

El movimiento obrero, que en teoría marxista sería la vanguardia de los movimientos sociales, no jugó tal papel, en parte porque los sindicatos oficiales estaban cooptados por los regímenes (con algunas excepciones, como el caso de Túnez) quienes lo usaban 
como un 'sindicalismo de bolsillo' de acuerdo a sus necesidades (Barreñada, 2011). Así, el sindicalismo independiente que floreció en medio de las revueltas, más que causa (que también lo fue) es consecuencia de las protestas ${ }^{8}$. Algo similar sucede con los partidos y las fuerzas de oposición que habían terminado por ser 'funcionales' al régimen.

Es ingenuo esperar que los movimientos sociales árabes conserven la heterogeneidad de sus banderas y al mismo tiempo, que no tengan disputas internas, mostrándose entonces al mundo como un bloque homogéneo, merecedor de su respeto y apoyo. Dicha falta de unidad se usa por ejemplo, para desacreditar a la oposición en Siria, cuya división interna merece una reflexión especial.

Bajo la sigla del ELS (Ejército Libre Sirio) confluyen un sinnúmero de expresiones armadas no siempre coordinadas entre ellas, sin que sus diferencias se resuelvan usando un mismo nombre porque, como dice Nietzsche: "la unidad del nombre no garantiza la unidad de la cosa". Incluso, algunas milicias no se consideran parte del ELS. La falta de unidad fue una de las causas del fracaso de la revuelta siria de 1925 contra los franceses, pero esto no hay que verlo necesariamente como un símbolo de descalabro. Tampoco estaba unificada ni homogénea la resistencia francesa contra el nazismo y los sandinistas se unieron apenas pocos meses antes de la caída de Somoza.

En el mundo árabe este tipo de confederaciones no son una rareza: Hizbollah nació de una confederación de grupos armados contra la ocupación israelí del sur del Líbano (1982-1985) ${ }^{9}$ y la Organización para la Liberación Palestina (OLP) es también una coalición de fuerzas. El Consejo Nacional Sirio (CNS) sigue siendo un aglutinador de la gran mayoría de sirios en el exilio, pero no es la única fuerza opositora: hay un gran número de fuerzas políticas contra Al-Asad. Estados Unidos cuestiona al CNS, al que reconocen en la medida que le sea funcional, pero al mismo tiempo amenaza con buscar un nuevo interlocutor. Por su parte, el ELS enfrenta tres problemas, la presencia de Al-Qaeda, el riesgo de cooptación por parte de los Estados Unidos y el más grave: la necesidad de coordinación militar en el terreno. Pero ninguna de esas tres realidades niega lo justa que es la lucha contra Al-Asad.

Unas revueltas árabes plagadas de variadas agendas cuya principal característica es la inexistencia de una única vanguardia (lejos de un modelo leninista), difícilmente podría tener una única organización militar. Su fortaleza es a la vez su riesgo, pero eso hace parte de su naturaleza plural. El desacuerdo de hoy no es una fatalidad antidemocrática. Sería útil entender que la guerra es una fase que no reemplaza el debate que vendrá cuando caiga el régimen y que los sirios podrán discutir en la arena política, cuál Siria quieren.

\footnotetext{
${ }^{8}$ Entrevistas del autor con varios líderes del movimiento sindical árabe durante el Foro Social Mundial, marzo de 2013, Túnez.

${ }^{9}$ Entrevista del autor con líderes de Hizbollah, Beirut, septiembre de 2013.
} 
Buena parte de la respuesta no está en el ELS ni en el CNS, ni mucho menos en la CIA que trata de pescar en río revuelto, sino en los Comités de Coordinación Local, creados desde marzo de 2011. La fe en las estructuras locales de base, que están en el día a día del frente de guerra, es en últimas, la garantía de que la revolución no termine, en su afán por unificarse, construyendo su propio verdugo.

Resumiendo, la negación de la vanguardia es un símbolo de rechazo a los modelos del pasado, temor al autoritarismo, desconfianza de los partidos políticos incluyendo a la izquierda tradicional y deseo de explorar la construcción de formas políticas más incluyentes. Ese mismo deseo explica la ausencia de líderes mesiánicos (caso en el pasado de Gadafi, Mubarak) que encarnen y/o representen en una sola cara y en una sola voz a la gente.

\section{Lección 4. La interacción con lo tribal}

Además de las tensiones políticas, hay en el escenario árabe otro tipo de instituciones que determinan la cotidianidad: las tribus y/o lo étnico y lo religioso. Hay países donde esto tiene un mayor peso que en otros (Libia, Yemen), o donde se ha querido leer la protesta solo y únicamente sobre la base de tensiones religiosas (Siria, Bahréin).

Se observa en general, una gran capacidad para ver por fuera y por encima de la tribu, de la etnia y de la religión (aunque no siempre es así). Muchos kurdos-sirios no tienen problemas con otros sirios en su lucha conjunta contra Al-Asad ${ }^{10}$, los chiíes explicitan que su lucha en Bahréin no es contra los suníes en cuanto tales sino contra el gobierno ${ }^{11}$, los aislados ataques a los cristianos coptos de Egipto fueron rechazados por la inmensa mayoría de musulmanes, etc.

Los escenarios en donde más se han levantado dudas con relación al papel de las tribus han sido Libia y Yemen. Sobre este escenario se ha tenido toda una mitología de condena al fracaso. Allí, durante los 42 años del régimen de Gadafi, Libia no tuvo partidos políticos ni organizaciones de la sociedad civil.

Se temió que como en Libia las tribus han sido de las pocas estructuras sociales con capacidad de movilización al final de la guerra, entonces lo tribal no sería superado por un ideal nacional y Libia entraría en una nueva dinámica de disputas. Pero no fue así, fue posible consolidar las organizaciones que participaron en las primeras elecciones en 60 años. En este proceso, 80\% de las personas en edad de votar lo hicieron, con más de 3.000 candidatos. Es cierto que hay 140 tribus, pero la mayoría de ellas no tiene más de 1.000 personas, siendo las más grandes los Warfalla y los Magariha. Las tribus sufrieron divisiones internas durante el levantamiento pues sus integrantes no actuaron simplemente como 'miembros de una tribu' (Fuentesanta, Lorca y James,

\footnotetext{
${ }^{10}$ Entrevistas del autor con kurdos en la frontera sirio-kurda, julio de 2012.

${ }^{11}$ Entrevista del autor con un líder de Bahréin en Beirut. Ver Currea-Lugo (2013, septiembre).
} 
2011). Renunciar a las tribus como espacio político, sin tener alternativas, llevaría al país a una crisis como sucedió en el caso de Somalia, pero lo que se observa en Libia es la capacidad de priorizar en este momento una propuesta política nacional y/o regional, por encima de los proyectos tribales.

También preocupa en Libia que las milicias -algunas de ellas, expresión militar más de lo local, lo tribal y/o lo étnico que de lo nacional- definieran la política, que Libia se hundiría en un Estado fallido bajo el control de los señores de la guerra, tal como Afganistán en 1989, pero no fue así. Las tensiones no pasan de choques esporádicos entre algunas milicias y acciones aisladas, de hecho el nuevo ejército libio se nutre de las milicias. Las manifestaciones, pidiendo su desmonte, no solo fueron respetadas sino seguidas de una campaña de recolección de armas en 2012; aunque en 2013 sí fueron objeto de ataques. Para este punto, lo relevante es la capacidad de movilización política por parte de las organizaciones sociales libias contra las milicias, más allá de su filiación tribal.

Algunas milicias islamistas siguen operando, pero eso no significa que Libia se reduzca a una guerra entre milicias. Como muestra de rechazo social, ciudadanos furiosos atacaron e hicieron huir a las milicias de 'Ansar Al-Sharia' de Bengasi, responsables de la muerte del embajador de los Estados Unidos.

En Libia hay banderas regionales y agendas locales, como la bandera negra de la región de Cirenaica, o la reivindicación de Bengasi como punto de nacimiento de la revuelta, pero eso no impidió la formación de una Asamblea Nacional. Es más, muchas de las críticas son más a favor de una Libia federal que de una separación del país.

Muchos de los que se escandalizarían con una ruptura de Libia, se quejan de la forma en que los colonizadores europeos delimitaron las fronteras africanas. Si rechazamos la forma como se crearon los Estados africanos ¿̇cuál es el problema con que se separen? ¿Por qué esa tardía defensa del Estado? El error está en pensar que los libios no pueden ser mayores de edad políticamente hablando, que no pueden acceder a agendas universales y reducirlos a los límites de sus regiones, sus tribus y su religión.

Por lo menos hasta hoy, Libia no está viviendo una lucha de señores de la guerra ni una división por tribus o por regiones, tampoco ha fracasado su institucionalidad en ciernes. Hay manifestaciones de todo tipo: contra el gobierno, por un modelo federal, por una mayor transparencia, por una mayor representación de las mujeres en la Asamblea Nacional, contra las milicias, etc. Estas marchas deben ser vistas como un síntoma de ejercicio de derechos, antes que una fractura social.

Podemos sugerir que el uso de los medios políticos y sociales de las etnias y las tribus no fueron simplemente una renuncia a banderas más universales, fueron el uso de los recursos organizativos con los que cuenta la sociedad para movilizarse. Es decir, los movimientos sociales no se sometieron a un discurso de lo étnico y/o lo tribal, sino que 
lo tribal y/o lo étnico estuvo finalmente puesto al servicio de los movimientos sociales. Este fue el caso del rechazo de las tribus a los crímenes del gobierno de Yemen en 2011.

\section{Lección 5. Cómo gestionar las tensiones con el Islam político}

Es ingenuo pensar que en una región de mayorías musulmanas el factor religioso esté ajeno a las acciones políticas, pero el debate es si los manifestantes actúan como ciudadanos o como creyentes. Aunque hay presencia de actores religiosos (como los Hermanos Musulmanes), mujeres con velo en las marchas y libros del Corán en manos de los opositores, nada indica que se trata de una revuelta de corte islámico (Chomsky, 2011). Eso no ha impedido la proliferación de discursos que sugieren, como dice Roy, una "geoestrategia del Islam” que explicaría todos los conflictos actuales (Roy, 2007, p. 11). Los debates centrales se dan en torno a: a) las organizaciones musulmanas en las revueltas; $\mathrm{y}$ b) en torno a la Sharía (que literalmente significa "camino al manantial") y que se traduce como las normas de derecho islámico que serían implementadas luego de las revueltas.

El crecimiento relativo de los salafistas en las elecciones de Egipto y el triunfo de una fuerza política islamista moderada en las elecciones de Túnez (Hizb Al-Nahda, el Partido del Renacimiento), contrasta con el arrollador triunfo del partido liberal en Libia (Alianza de Fuerzas Nacionales) en unas elecciones en que la segunda fuerza, Los Hermanos Musulmanes, apenas lograron algo más del 10\%.

A partir del 11 de septiembre de 2001, las tensiones entre Occidente y el mundo musulmán han ido en aumento. La creciente islamofobia ${ }^{12}$, el terrorismo de Al-Qaeda, la 'islamización' de algunas causas nacionalistas como el caso de Filipinas y Chechenia ${ }^{13}$, (no así en el caso palestino ${ }^{14}$ ) han ahondado en el debate sobre el carácter político del Islam o el carácter islámico de toda acción política de los musulmanes.

La noción de ‘Islam político’ es ya discutible: ya sea porque toda religión tiene detrás una propuesta de organización social que la convierte por definición, en una propuesta también política, o bien porque en sentido restrictivo, el Islam no es una propuesta política sino que trasciende la política y por tanto la política como fin contradice la esencia del Islam. A pesar de tal tensión conceptual, la categoría ha hecho carrera dentro del mundo académico.

También es necesario distinguir entre el Islam político y la propuesta de Al-Qaeda: muchas organizaciones armadas de orientación islámica rechazan abiertamente a tal

\footnotetext{
${ }^{12}$ Por ejemplo, luego del asesinato de Theo Van Gogh en Holanda a manos de un joven holandés de origen marroquí (2004), por lo menos una docena de mezquitas y sitios asociados con el mundo musulmán fueron atacados y la noticia de tales ataques no pasó de ser una pequeña nota en los periódicos locales.

${ }^{13}$ Para el caso de Chechenia, ver: Hughes (2007).

${ }^{14}$ Para Olivier Roy, la lucha palestina "es ante todo la lucha por la liberación de un pueblo" y no una lucha islámica. (Roy, 2003, p. 24).
} 
grupo: es el caso de Hamas en Palestina, de Hizbollah en Líbano, de los rebeldes de Ogaden en Etiopía, del Frente Polisario en Sahara Occidental, del Movimiento por la Justicia y la Equidad en Darfur, entre otros ${ }^{15}$. Lo mismo sucede a nivel individual: "lo que caracteriza a numerosos hombres de Al-Qaeda es precisamente la ruptura con el mundo musulmán al que pretenden, sin embargo, representar” (Roy, 2003, p. 25), pero que llevan dentro de sí tres rupturas: "con el país de origen, con la familia y con el país de acogida” (Roy, 2003, p. 175).

Tampoco hay una posición única del Islam frente a las revueltas árabes: en el caso de Arabia Saudita, el Consejo de Grandes Ulemas de Arabia Saudí prohibió las protestas mediante una fatwa (Atuán, 2011) mientras otros líderes religiosos se han pronunciado a favor o en contra (Libia, Yemen) o validando las protestas si estas son de suníes o de chiíes (Egipto, Siria, Bahréin). En Siria, más allá de agendas religiosas, hay ricos alawitas en el exilio que han financiado rebeldes suníes (Roy, 2003, pp. 25 y 175).

Las organizaciones islámicas tienen a su favor, el anti-americanismo y paradójicamente hasta la islamofobia, pasando su capacidad de garantizar 'cero corrupción' aún en contextos difíciles (como Hizbollah y Hamas ${ }^{16}$ ) y su capacidad para crear redes sociales muy fuertes recuperando una identidad perdida. En el caso de los Hermanos Musulmanes, "los principales instrumentos del islamismo no son las bombas ni los rehenes, sino las clínicas y las escuelas” (Esposito, citado en Lampridi-Kemou, 2011, p. 70). Sin embargo, en su contra juega su ambigüedad con los derechos humanos y especialmente, con los derechos de las mujeres.

Su prioridad no es el poder sino la islamización de la sociedad y ese es un proceso a largo plazo que no puede imponerse por decreto sino que se hace con trabajo cotidiano. Para ellos, el poder político no es un fin sino un medio. Como dice Ignacio ÁlvarezOssorio, la renuncia a la creación de un Estado islámico, la aceptación del pluralismo político, el rechazo a la violencia y el diálogo con la oposición son los pilares de su estrategia (Álvarez-Ossorio, 2008). Y como agrega Roy, “casi todos los movimientos islamistas han abandonado el terreno de la violencia política y se han vuelto más nacionalistas que islamistas" (Roy, 2003, p. 35).

Un líder egipcio de las revueltas, en el marco de este debate me contestó: “Los Hermanos Musulmanes son más liberales que la extrema derecha francesa y Bush fue menos democrático que los Hermanos Musulmanes. Si uno acepta la democracia, tiene que aceptar que ellos se organicen y participen"17.

\footnotetext{
${ }^{15}$ Como trabajador humanitario he tenido la posibilidad de hablar con voceros de estas organizaciones y de seguir sus documentos, lo que justifica mi afirmación.

${ }^{16}$ Entrevista del autor con el Ministro de Salud de Hamás, Basel Naim, en Gaza, junio de 2008.

${ }^{17}$ Entrevista del autor con Gamal Eid (director ejecutivo de la Red Arábiga por la Información para los Derechos Humanos, basada en El Cairo) El Cairo, abril 2011 (Currea-Lugo 2011, pp. 63-64).
} 
Este aparente giro hacia un modelo como el de la democracia cristiana también ha sido identificado por Tariq Ramadán, quien dice que los partidos musulmanes están mirando el modelo turco (Yalman, 2011, pp. 79-87), pero el modelo turco tiene dos críticas: el gran poder que tienen los militares y el poco reconocimiento a los derechos de las minorías. Además, los grupos musulmanes, por ejemplo los Hermanos Musulmanes, en cuanto actores religiosos, buscan la islamización de la sociedad desde la base y no desde el poder político el cual, en el mejor de los casos, sería un medio y no un fin en sí mismo, pero ese medio es actualmente frágil y cambiante como para apostar todo a un solo caballo.

En el caso de la Sharía, hay que acotar que las revueltas no son esencialmente laicas, aunque cuestionen algunas lecturas religiosas y culturales de la sociedad. En Libia, muchas de las afirmaciones sobre la Sharía por parte de los rebeldes no son una involución sino la ratificación de las costumbres ya imperantes durante la época de Gadafi y por tanto, son acusables de continuismo pero no de retroceso.

Ahora el debate es cómo resolver las tensiones entre la Sharía y las reivindicaciones compatibles con los derechos humanos. Anterior a las revueltas, esta tensión se resolvía de tres maneras: a) confinando la Sharía al estatuto personal, dejando el resto de cuestiones al derecho positivo; b) declarándola ley del Estado, como es el caso de Arabia Saudita y del modelo talibán; c) haciendo prevalecer la lógica política y del derecho positivo sobre la Sharía (Roy, 2007, p. 54).

Dice Roy que "de hecho, el estatuto de la mujer y la apostasía son los dos (y únicos) escollos en la cuestión de compatibilidad del islam con los 'valores occidentales"' (Roy, 2007, p. 55), pero esos dos aspectos no son poca cosa. Para otros autores "no hay nada en las sociedades islámicas que las haga incompatibles con la democracia, los derechos humanos, la justicia social o la gestión pacífica de los conflictos, como pretenden quienes defienden la existencia de una excepción islámica” (Alvarez-Ossorio y Gutierrez de Terán, 2011, p. 15). Sin embargo, para un marxista, siendo la religión el opio del pueblo, la idea de la emancipación humana pasaría por la emancipación de la religión (Marx, 1844).

Como dice George Corm, "el Islam [es] con demasiada frecuencia utilizado abusivamente como marcador identitario e histórico exclusivo de los diferentes pueblos de la región, pero también como única clave de explicación” (Corm, 2009, p. 15), lo que constituye uno de los grandes errores de Occidente. Lo curioso es que gobernantes de Egipto, Libia, Siria, Jordania y Yemen han usado el mismo argumento: el miedo al 'islamismo radical' para justificar su permanencia en el poder. En palabras de Khalil Al-Anani (2012):

“[...] la cuestión no es el papel y el espacio que pueda tener la religión en esta incipiente esfera (una nueva esfera pública propia que refleje las ideas y las aspiraciones de los jóvenes árabes), sino más bien el impacto que tendrá sobre la religión el que esta esfera se emancipe del Estado. [...] la religión -insisto, las dimensiones culturales y simbólicas de la 
religión- ha desempeñado un papel vital en las revueltas árabes. Sin embargo, este papel no ha sido rígido ni estático. A pesar de la aparición del islamismo en los momentos posteriores a las revueltas, estaba claro que los movimientos islamistas se inclinaban por el cambio. Cuanto más se abra esta esfera para incluir a los islamistas, menos se resistirán al cambio y menos retrógrados se mostrarán. La amenaza para las incipientes democracias árabes no provendrá de la religión, ni del islamismo, sino más bien de aquellos que luchan por reproducir las viejas estructuras autoritarias y de ese modo poner fin a la Primavera Árabe.

En rigor, un Estado de naturaleza confesional por más laico que sea siempre tendrá una distinción entre el creyente y el no-creyente, el kafir. Así las cosas, las banderas de la inclusión política y la justicia social se abordan ya no desde el concepto de persona ni desde la relación Estado-ciudadano, sino desde el concepto de mérito que a su vez se define por su pertenencia o no a un grupo religioso, incluyendo el puesto que tal religión otorga a sus adeptos (por ejemplo, a las mujeres).

No obstante, en las recientes elecciones de Marruecos, de Túnez y de Egipto, los partidos con orientación religiosa han ganado espacio social, legitimidad y poder político. Pero esto no hay que mirarlo con paranoia, ni siquiera en el caso de los derechos de las mujeres, como lo dice Nada El-Kouny (2011). Dicho de otra manera,

[...] las formaciones islamistas se han beneficiado del hartazgo político existente, al recabar el voto de castigo hacia unos regímenes autoritarios deslegitimados que se perpetúan en el poder [...] La instrumentalización que hacen de la cuestión religiosa les ha servido para atraerse las simpatías del electorado en unas sociedades en las que lo religioso impregna por completo la esfera pública. (Alvarez-Ossorio y Zaccara, 2009, p. 15)

Más allá de esos debates semánticos sobre la cuestión religiosa (importantes pero secundarios en el presente debate) es necesario recordar que, a pesar de que muchos insistan, no estamos ante una guerra de civilizaciones ni mucho menos de religiones: Al-Qaeda atacó Wall Street, no atacó el Vaticano. "Si Occidente no es el cristianismo, ¿por qué el Islam habría de ser Oriente?” (Roy, 2003, p. 21).

Marx decía que la religión "es el opio del pueblo", pero antes aclaraba algo que es relevante para entender tanto el papel de la religión musulmana en las fases previas a las revueltas de cara al autoritarismo y a las políticas neoliberales, como para entender el papel creciente de los musulmanes organizados políticamente en las revueltas y en la fase de reconstrucción de los nuevos países: "la religión es [...] el alma de un mundo sin corazón, así como el espíritu de una situación sin espíritu” (Marx, 1844).

Los musulmanes están en las calles de la misma manera que la democracia cristiana mueve una agenda política que va más allá del Nuevo Testamento y del Vaticano. 
Para Olivier Roy, los islamistas tienen dos caminos: el paso a un modelo como el de la democracia cristiana o el paso a un neo-fundamentalismo (Roy, 2007, p. 49) y eso se observa hoy en las calles del mundo árabe.

\section{Lección 6. Cómo enfrentar la estigmatización de la lucha}

La estigmatización de las luchas sociales es una constante mundial, ya sea contra los indígenas de Bolivia o contra las minorías de Birmania; no tendría por qué ser diferente en las revueltas árabes. Denigrar de la oposición, caricaturizarla, presentarla como organizaciones al servicio de agencias extranjeras -como la CIA-o de redes internacionales de terrorismo - como Al Qaeda- ha sido una constante por parte de gobiernos, de algunos medios de comunicación, de algunos intelectuales e incluso, de contradictores dentro de los mismos bloques de oposición, como se ejemplifica a continuación.

Los opositores de Gadafi fueron presentados como alcohólicos y drogadictos, como ocupantes extranjeros (Al Jazeera, 2011 febrero 21) al servicio del "sionismo y el imperialismo" (El País, 2011 febrero 19); los opositores de Al-Asad como fruto de un complot ${ }^{18}$ igual que en Túnez donde todo era obra de "un complot extranjero, organizado por Al Qaeda en el Magreb Islámico” (Martínez, 2011, p. 37). En Yemen dijeron que las revueltas “estaban dirigidas desde Tel Aviv y bajo la supervisión de Washington" (Saleh, citado en Daud Sharián, 2011 marzo).

Esto se alimenta de dos lógicas: que los regímenes no habían hecho mérito alguno para ser expulsados por sus pueblos y que el poder de la CIA era inconmensurable dentro de la población árabe. Es conocido que las potencias tratan de posicionarse en el nuevo escenario, pero eso no hace a las potencias líderes de las revueltas.

Habría que diferenciar entre una violencia que depende de una agenda religiosa (caso del grupo Boko Haram en Nigeria y de Al-Shabbab en Somalia) y otra que es ejercida por un grupo de creyentes de una misma fe pero cuya expresión violenta corresponde más a una agenda política nacionalista (esta tensión se ha dado en Mali, Chechenia y Darfur, por ejemplo). Uno de los grandes perdedores de las revueltas es precisamente Al-Qaeda y el terrorismo como discurso político (aunque dicho grupo ha avanzado en Siria debido a las particularidades del conflicto).

Un elemento común a buena parte del mundo árabe es su rechazo a Israel: por su propuesta sionista, por las guerras que han perdido los árabes (1948, 1967 y 1973), y/o como parte del sentimiento anti-estadounidense. Por tanto, cualquier coincidencia discursiva que se pueda hallar entre un grupo opositor e Israel pareciera elemento suficiente para reducir las voces opositoras a 'agentes del sionismo'. Israel es otro de los grandes perdedores y por ende el lobby judío y sus socios en los Estados Unidos;

${ }^{18}$ Discurso de Bashar Al-Asad, Siria, 20 de junio de 2011. 
su famosa predicción de que los árabes eran 'incompatibles' con la democracia -lo que algunos llaman la 'excepción árabe'-, quedó desmentida por la historia reciente.

Un problema de fondo es la incapacidad, tanto en la derecha como en la izquierda, de desprenderse del pensamiento propio de la Guerra Fría. En el caso de la izquierda prima una lectura dicotómica sobre las revueltas en general y sobre el caso sirio en particular. Cuando los rebeldes llegaron a Trípoli, Libia, voceros de cierta izquierda dijeron que los videos eran 'made in Hollywood', como dijeron luego sobre las armas químicas de Siria. Para algunos la revuelta de Túnez fue planeada en Paris, la de Egipto en Tel Aviv y la de Siria en Washington. Claro que allí están la CIA, El Mosad, Al-Qaeda y similares, pero de ahí a reducir las banderas de las calles árabes a simples conspiraciones es, entre otras cosas, negar que los árabes puedan pensar políticamente.

Para cierta izquierda, no habría razones para protestar en el mundo árabe porque este era casi un paraíso terrenal sin injusticias ni inequidades. Esa izquierda minimiza la justicia de las causas locales y solo mira la geopolítica: si cae Siria lo único que cuenta es que desde allí se pudiera atacar a Irán. A pesar de las pruebas del uso de armas químicas en Siria, cierta izquierda iguala Irak y Siria diciendo: si no había tales armas en Irak, tampoco las habrá en Siria. En Siria la táctica es: negar los hechos (no hay armas químicas), poner al régimen en el papel de víctima (Estados Unidos odia a Al-Bashar porque este no se somete), negar la justeza de los rebeldes (se trata de mercenarios extranjeros y de Al-Qaeda), ocultar las injusticias locales (dar prioridad a la geopolítica) y desviar el debate (como Israel usó fósforo blanco en Palestina en 2008 y sigue impune, entonces tampoco se podría condenar a árabe alguno).

Una opción para evitar la estigmatización es entonces, disminuir sus causas, presentarse como 'buenos muchachos', desmentir antes que afirmar. El problema es que esa estrategia impediría asumir el mensaje central de los movimientos sociales árabes al estar supeditado a su nivel de rating, esto ancla el movimiento social a la opinión pública y le arrastra a sacrificar las banderas reales en aras de las políticamente correctas, pero eso tiene un costo muy elevado que los árabes ni piensan pagar ni está en la naturaleza de sus luchas. Ni a los Hermanos Musulmanes ni a los grupos salafistas (ni al movimiento social árabe en general) les preocupa la aceptación en términos de los medios occidentales.

Decía Marx: "los obreros franceses no podían dar un paso adelante, no podían tocar ni un pelo del orden burgués, mientras la marcha de la revolución no se sublevase contra este orden" añadiendo que "sin revolucionar completamente el Estado francés no había manera de revolucionar el presupuesto del Estado francés” (Marx, 1850, pp. 98 y 168-169); escenario dentro del cual la estigmatización de los cambios es una constante: "toda reivindicación, aún la más elemental reforma financiera burguesa, del liberalismo más vulgar, del más formal republicanismo, de la más trivial democracia, es castigada en el acto como un 'atentado contra la sociedad' [...]” (Marx, 1850, pp. 219). Podemos 
concluir que no habría peor árabe que el que no quiere ver o peor aún, que el que no quiere ser visto como un ser 'políticamente incorrecto'.

\section{Lección 7. Los aliados internacionalistas o cómo lidiar con los oportunistas}

Cuando empezaron las revueltas árabes, muchos trataron de robarse sus banderas pero eso no significa que no haya legitimidad en las protestas, lógica que busca negar así todo lo auténtico de las banderas de los movimientos sociales árabes.

Una vez se dan las protestas, se dispara la tendencia de las superpotencias (Estados Unidos, Reino Unido y Francia, principalmente) por posicionarse para sacar provecho de ellas, lo que tampoco es una novedad, ni una fatalidad. Así mismo actúan los países con claras agendas regionales (Turquía, Irán, Israel, Arabia Saudita). El problema está en la tendencia inaugurada por los mismos ya ex gobernantes (Mubarak, Ben Ali, Gadafi) de presentar a los opositores como 'agentes al servicio' del imperialismo, de Al-Qaeda, del Mosad o de todos juntos. Hay que resaltar que el mejor escenario para los Estados Unidos y para las industrias del petróleo es un Oriente Medio sin cambios (excepto frente al caso iraní).

Pareciera que observadores ajenos al mundo árabe reconocen inmediatamente que los aliados de los rebeldes estarían controlando las mentes árabes y dictando sus agendas; pero los árabes que están en las calles, no lo ven. Eso no solo es incorrecto sino que presupone que el árabe es fácil de engañar. Es cierto que hay claras tensiones por el control de la región, pero ninguna de esas argumentaciones de la geopolítica regional son suficientes para convertir al pueblo árabe en peón del ajedrez internacional que por tanto, pueda sacrificarse impunemente.

La agenda de las víctimas de las masacres y de los manifestantes pide ya un posicionamiento internacional en su apoyo, como sucedió en Libia. Pero el ajedrez internacional de Libia es diferente al sirio. Siria es amigo de Irán, enemigo de Israel y soporte tanto de grupos palestinos como libaneses. De caer Siria, podría ser usado como una plataforma para atacar a Irán, (sumándose a las más de 30 bases militares de Estados Unidos que ya lo rodean). La caída de Siria, en el plano internacional, rompería además los lazos entre Irán y Hizbollah, para beneficio de Israel y beneplácito de los Estados Unidos y sus aliados.

Un sector de la comunidad internacional quiere atacar a Irán y la caída de Siria facilitaría las cosas, pero eso no es un argumento que convenza a los rebeldes ni los convierta en agentes de la CIA. La torpeza de Asad aumenta el riesgo de que las revueltas sean 'secuestradas' por Occidente al empujar, como en Libia, a que los rebeldes tengan el dilema de 'alquilar el alma al diablo' o de morir sin conseguir nada.

El problema no es tanto el oportunismo francés y estadounidense como la ceguera del régimen. Y en un pensamiento típico de la Guerra Fría se excluye del análisis al pueblo 
sirio. Se sacrifica lo local en aras del análisis geopolítico en el que los sirios son peones del ajedrez internacional. La legitimidad de los rebeldes no debería determinarse por quienes les apoyan, sino por su agenda, por contra quién luchan. Así las cosas, los sirios están atrapados: por un lado está el gobierno sirio insensible a los reclamos de su pueblo (con el apoyo de Rusia y China) y por el otro, la postura de Estados Unidos, más pendiente de su propia agenda en la región que de la suerte de los sirios.

La adaptación de los rebeldes sirios a los potenciales donantes internacionales es bastante ilustrativa ${ }^{19}$. Los rebeldes enfrentan, además de la falta de medios y los reveses militares, la división de sus donantes, el aumento de la capacidad militar del régimen por el apoyo de Hizbollah y de Irán, choques internos y una marcada satanización. La prensa ha creado un discurso en el cual los manifestantes pacíficos de 2011 desaparecieron y fueron desplazados por islamistas radicales, negando que muchos de los que en 2011 levantaban una pancarta ahora levanten un arma. Esa tendencia ha contribuido a negar también la existencia de una oposición armada pro-democrática y/o laica.

Además de los rebeldes del ELS (Ejército Libre Sirio), hay dos organizaciones yihadistas pro Al-Qaeda: Jabhat Al-Nusra (“El Frente de la Victoria”) y la organización del Estado Islámico de Irak y Sham (ISIS, por sus siglas en inglés) cuyas banderas negras recuerdan su vínculo explícito con Al-Qaeda, aunque estos grupos no superarían 15\% de los rebeldes. La bandera de ISIS se observa en algunas calles de Trípoli, al norte del Líba$\mathrm{no}^{20}$. Estos últimos grupos van más allá de la caída del régimen y realmente luchan por el establecimiento de un régimen islamista. El grado de control social a la población por parte de un grupo cambia según su forma de entender el Islam, pero su capacidad dependería más del apoyo externo en armas y municiones.

El avance de los grupos más radicales, ya sea por convicción o por los recursos que disponen, es real. Los enfrentamientos entre el ESL y los grupos pro-Al Qaeda se dan desde la aparición misma de Al-Qaeda en Siria $^{21}$. Algunos rebeldes del ESL reconocieron que han sido perseguidos y desplazados por dichos grupos ${ }^{22}$.

Decía una líder siria que debido a la disponibilidad de armas y recursos en Al-Nusra, muchos sirios - por razones pragmáticas- se unen a este grupo porque es el que más posibilidades ofrece. Algunos mecenas de Kuwait estarían sirviendo a la causa más radical. Detrás de cada expresión hay uno o más financiadores: los Hermanos Musulmanes reciben apoyo financiero de Qatar, mientras Arabia Saudita patrocina a los suníes en

\footnotetext{
${ }^{19}$ Basado en entrevistas del autor con rebeldes sirios en Líbano, septiembre de 2013. Ver mi análisis del espectro de los rebeldes en: De Currea-Lugo (2013, octubre 17).

20 Observación del autor en Trípoli, Líbano, septiembre de 2013.

${ }^{21}$ Entrevista del autor con Khaled Khoja, líder del entonces Consejo Nacional Sirio, Estambul, julio de 2012.

${ }^{22}$ Entrevista del autor con miembros del ELS, Líbano, septiembre de 2013.
} 
general, aunque según dicha líder siria hay grupos privados de saudíes, de Kuwait y de los Emiratos que estarían detrás de yihadistas.

Pero esa financiación compra soldados, no corazones. Como dice el Arab Reform Initiative, hay que diferenciar entre los donantes a la guerra y los que hacen la guerra: Siria es más un campo de batalla entre donantes islamistas y entre estos y los laicos, que entre creyentes. Curiosamente, agrega el estudio del ARI, algunas katibas (brigadas) se ponen un nombre de acuerdo al gusto del donante y algunas hasta tienen dos nombres, uno en números para los donantes laicos y otro nombre radical para los donantes islamistas (Kodmani y Legrand, 2013, septiembre).

Otro aliado (discutible) sería la banca internacional. En la primera de las revueltas, la tunecina, durante el primer año del gobierno de coalición, las tensiones principales se derivaron de dos agendas paralelas: la construcción de la democracia y la (re)construcción del Estado social, enmarcada en un programa mínimo para mantener la unidad. Además, se complicó la situación económica con la caída en la producción de fosfatos, las tensiones en las fronteras -Libia, Sahel-y la herencia de Ben-Alí.

Pero el gran problema no es el salafismo ni la cultura política vertical, sino la falta de recursos: Túnez podría quebrarse. Una de las salidas es un préstamo internacional, pero el Fondo Monetario Internacional (FMI) exigiría la reducción del subsidio a la energía eléctrica y la reforma del sistema de pensiones ${ }^{23}$. Con lo cual, para salvar la revuelta hay que sacrificar la revuelta. Eso mismo pasa en Libia y en Egipto. Así las cosas, el principal enemigo de las revueltas árabes es el FMI.

Hay otra tensión relacionada con los aliados: la tensión entre la construcción de miradas nacionales o el discurso internacionalista. El nacionalismo en Bahréin permite no caer en discusiones religiosas al revindicar la condición de bahreiní por encima de la religión (una de las consignas más gritadas es: Ni suníes, ni chiíes, todos somos bahreiníes), pero ese nacionalismo puede prevenir la solidaridad internacional: la marcha contra el gobierno de Al-Asad en El Cairo, a mediados de julio de 2012, apenas movilizó unos pocos cientos de personas frente a la embajada siria ${ }^{24}$.

Si bien una encuesta mostró que 70\% del mundo árabe apoyó las marchas de Túnez y $80 \%$ las de Egipto, y que 70\% ve el mundo árabe como una sola nación, eso no implica que la mayoría de la gente pase -en términos de internacionalismo- de la opinión a la calle (Arab Center For Research and Policy Studies, 2012). Es decir, la división del mundo árabe en países-estanco, por medio de Pacto Sykes-Picot (de 1916), es un 'pecado original' que el mundo árabe no ha exorcizado.

\footnotetext{
${ }^{23}$ Entrevista del autor con Khalil Zaouia, Ministro de Asuntos Sociales de Túnez, Túnez, marzo de 2013.

${ }^{24}$ Observación directa del autor, El Cairo, Egipto, julio de 2012.
} 
Otra cosa es el discurso internacionalista, figura que tiene su gran referente en la Guerra Civil Española y que fue manipulada por el bloque socialista para justificar la invasión a Afganistán; hoy tiene una nueva oportunidad precisamente de la mano de los grupos que lucharon contra dicha invasión, una suerte de 'internacional islamista' que cuenta, hoy por hoy, con lo que la izquierda ha perdido: una base social transnacional que le permite participar tanto en la guerra de Libia como en la de Siria. Eso que hemos llamado aquí 'internacionalismo islamista' es parte de la misma noción del Islam, en el cual no hay naciones sino que toda la tierra es, en el fondo, una gran mezquita (un "Dar-El-Islam”).

\section{Lección 8. El uso de los medios: de Facebook al fusil}

Lo virtual está de moda, como si fuera el espacio real de la política, queriendo convertir la lucha por el poder en una gran matrix. Libia bloqueó el acceso de críticas contra el gobierno a las páginas web y Bahréin las cerró y detuvo ciber-opositores. Siria ha censurado Facebook y Youtube. En Libia, activistas que habían puesto información sobre las marchas en Facebook, fueron detenidos (Human Rights Watch, 2011 febrero). La Agencia Tunecina de Internet rastreó y censuró redes sociales y varios blogueros y ciber-activistas fueron capturados, entre ellos los que habían puesto información en Facebook sobre las marchas (Martinez, 2011, p. 33).

Mubarak apagó los servicios de telefonía e Internet durante varios días. En Túnez el asesinato del bloguero Khaled Said, en junio de 2010, dio origen a una red virtual de más de medio millón de personas en Egipto. Hasta Saif El-Islam se pronunció al respecto: "hay opositores que han querido imitar lo sucedido en Egipto y servirse de lo que se conoció como la 'Revolución del Facebook”"25.

Es curioso cómo se autodefine el "Movimiento de Jóvenes 6 de Abril" de Egipto, basándose en su uso de las tecnologías: "nos consideramos a nosotros mismos y somos considerados [...] como un movimiento juvenil original basado en el empleo de las nuevas tecnologías y los nuevos medios de comunicación, que empleamos profundamente para movilizarnos, comunicarnos y organizarnos" ${ }^{26}$.

Pero hay un error al confundir los medios con los fines e incluso, hablar de la 'revolución del Facebook', donde bastaría un simple mensaje de texto para que caiga un dictador. Internet no es la causa y se necesitaron marchas, vigilias, tomas de plazas y muertos para que los gobiernos tambalearan.

Las revueltas previas fueron posibles sin Facebook. De hecho, la penetración de Internet en el mundo árabe es solo del 21\% (Alvarez-Ossorio y Gutierrez de Terán, 2011, p. 16) y el uso de Facebook con fines políticos era, hasta hace poco, casi marginal

\footnotetext{
${ }^{25}$ Discurso de Saif Al-Islam Gadafi, Libia, 21 de febrero de 2011.

${ }^{26}$ Pasquín del Movimiento de Jóvenes 6 de Abril, Egipto, 15 de julio de 2011.
} 
(Fauad, 2010, pp. 93-101). En Yemen, la poesía tribal jugó un papel importante entre comunidades sin acceso a Internet (Hamad, 2011, p. 90). En Egipto, los seguidores de Mubarak también recurrieron a Facebook ${ }^{27}$. Una prueba del fracaso de Facebook fue la convocatoria a los 'Días de la Ira' en Siria el 4 y 5 de febrero de 2011 a la que muy pocos se sintieron llamados, diferente a las protestas de marzo que fueron convocadas luego de la dura represión de las autoridades en Daara contra los jóvenes. Los muertos de las protestas en los diferentes países no son virtuales y tal vez la enseñanza más importante sea: triunfar en la web no significa triunfar en las calles.

Se olvida, como me decían los jóvenes de Jordania ${ }^{28}$, que muchos viejos que no tienen Twitter ni Facebook se sumaron a las marchas, que la 'red de mezquitas' actuó en algunos casos mejor que las redes virtuales y que, en el caso de Egipto, algunos activistas visitaron barrio por barrio para explicar el motivo de las protestas ${ }^{29}$. Además, los muertos de Siria y de Libia no son virtuales, que la Plaza de la Liberación en El Cairo no estaba llena de blogueros sino de gente de a pie. Y tal vez lo más importante, que triunfar en la web no significa triunfar en las calles, Yemen lo aprendió rápido y siguió el ejemplo represivo de Bahréin.

El segundo debate sobre los métodos es el de la guerra y la paz. Cada vez parecería más obvio que la distinción entre pacifistas y no-pacifistas es un invento europeo de nuevo cuño, antes que una reflexión universal. Ni los rebeldes sirios, ni los grupos de manifestantes egipcios que han recurrido algunas veces a la violencia callejera, ni los combatientes en Libia, se plantean dicha dicotomía.

Entre los árabes entrevistados, no existe la falsa tensión entre métodos pacíficos y violentos. Para la gente es simplemente una distinción entre métodos y no entre fines; no están enfrascados en la dicotomía latinoamericana respecto a la lucha armada, en la cual es más revolucionario usar armas y más reformista no usarlas. Los dos métodos sobreviven en Siria y la opción por uno o por otro (en Yemen, Libia, Túnez, Siria) ha dependido del contexto político y no de una racionalidad preconcebida frente a dichos métodos.

Cayó Gadafi por las armas, Ben Alí por las protestas pacíficas -aunque hubo asaltos a estaciones de policía y edificios públicos- (Martínez, 2011, p. 30) y Mubarak y Saleh por una mezcla que incluyó violencia y métodos pacíficos (aunque en diferentes proporciones) y que en el caso de Egipto continuaron después de la caída de Mubarak ${ }^{30}$. Pero el debate no es si la paz o si la violencia. Es necesario precisar que la violencia no es

\footnotetext{
${ }^{27}$ Al-Ahram Weekly, El Cairo, 28 de abril - 4 de mayo de 2011.

${ }^{28}$ Entrevistas con un grupo de jóvenes activistas con el autor, Amán, Jordania, mayo de 2011.

${ }^{29}$ Entrevista del autor con Nada El-Kouny, periodista de Ahram Online, enero de 2012.

30 Por ejemplo, "Violent clashes in Alexandria", Al Jazeera, marzo 4 de 2011; "Clashes erupt around Cairo's Tahrir Square", Al Jazeera, abril 9, 2011.
} 
menos violencia porque sea de masas, ni que los caminos de la paz son menos valiosos porque sean recorridos por unos pocos. No es un debate de números.

En los cuatro casos el contexto determinó el camino y el líder definió en parte, con sus decisiones, las opciones de la oposición. Ben Alí entendió a tiempo lo ineludible y evitó un baño de sangre. Mubarak se demoró un poco, lo que significó varios centenares de muertos.

Los ejércitos y los cuerpos de policía jugaron papeles diferentes. Las policías fueron el aparato represivo, mientras que los ejércitos inclinaron la balanza a favor de los manifestantes (Túnez, Egipto antes de la caída de Mubarak) o se dividieron (Libia, Siria, Yemen). En Túnez, el general Rachid Ammar, jefe del Estado Mayor, fue destituido por negarse a atacar a los civiles, mientras en Yemen, el general Ali Mohsen Al-Ahmar desertó del ejército anunciando su decisión de proteger a los estudiantes.

La guerra siria no fue 'fabricada' por radicales, de la misma manera que las marchas pacíficas del comienzo no eran la expresión del reformismo o de cobardía. Muchos sirios reconocen que hubo un proceso evolutivo desde las marchas pacíficas hasta la lucha armada donde, curiosamente, no aparece el debate (como el que se vive en otras partes del mundo) en el cual el método se fusiona en su análisis con el fin ${ }^{31}$.

El camino para llegar al poder no es garantía de mayor ni de menor democracia, ni de reforma o revolución en el período posterior a la dictadura; hay una percepción errónea de asociar los cambios revolucionarios a la violencia y las reformas a movimientos no violentos, confundiendo las agendas con los medios.

Sobre Libia nos dijeron que como el cambio fue a través de la violencia, un modelo participativo no era ya posible; que la revuelta, por su pecado original, estaba condenada y que ganarían los fanatismos religiosos. A diferencia de Túnez y de Egipto, en Libia las elecciones fueron ganadas por el partido liberal, con más del $48 \%$ de los votos. Una coalición de 58 organizaciones, la Alianza de Fuerzas Nacionales, ganó las elecciones de la Asamblea Constituyente, quedándose con 39 de los 80 escaños para partidos políticos. A pesar de la fragilidad del contexto, solo 8 de 6.629 puestos de votación no pudieron abrir.

En Egipto, luego de la salida pacífica de Mubarak, el ejército que se erigió como el 'guardián de la revolución' sigue siendo cuestionado por violaciones de derechos humanos. No podemos decir que Libia será menos democrática que Egipto porque la toma del poder se hizo por medios violentos. El problema es que tanto en la guerra como en la paz, el militarismo ha estado presente en las filas de los rebeldes ${ }^{32}$.

La tensión no es entre paz y violencia, sino en el sometimiento o no a ciertos principios (tolerancia, inclusión, respeto a la población civil). Decir que 'a lo mejor' por

\footnotetext{
${ }^{31}$ Entrevistas del autor con opositores sirios en Damasco (mayo 2011), frontera con Turquía (julio 2012) y Líbano (septiembre 2013).

32 Para el caso de Libia, ver: Human Rights Council (2011, junio 1).
} 
métodos pacíficos hubiera caído Gadafi es hacer ‘política ficción’; la realidad indica que cayó gracias a la lucha armada. Pero ese modelo libio hubiera generado en Egipto una ruptura social innecesaria existiendo caminos para una salida negociada. La paz como dogma en Libia solo hubiera servido para que el dictador se eternizara.

Satanizar a la guerra o a la paz es ingenuo. Cada pueblo y cada momento histórico fija un camino que depende de muchas variables y no de fórmulas preconcebidas, ni de gritos de guerra irresponsables, ni de cándidas banderas de paz.

Los Comités Locales de Siria han manifestado su opción por las vías pacíficas y su cuestionamiento a la lucha armada por las consecuencias que esta pueda generar: "la militarización de la revolución reduciría el apoyo y la participación popular en la revolución" 33 . Pero los hechos parecen demostrar la convivencia entre marchas y acciones militares. En el mismo sentido, Libia mostró que la guerra no dependía de si esta reducía el apoyo popular sino de si la protesta pacífica era un camino eficaz.

Engels decía a mediados del siglo XIX que "no se nos puede seguir cerrando el acceso a la sede del parlamento (Rejchstag). Entraremos, no cabe duda; lo único que se discute todavía es por qué puerta” (Engels, 1895).

El problema de los métodos es, para resumir, que las redes sociales son un apoyo a la calle, pero no la remplazan. Y que la dicotomía paz-guerra no es universal: la pazy la guerra, es un asunto de métodos y contextos más que de principios. No reducen a reformistas a los que no toman las armas ni ensalzan como revolucionarios a quienes toman las armas; es decir: no existe una forma de lucha superior sino una forma de lucha necesaria.

\section{Lección 9. De la movilización social a la organización política}

La tensión sentida en 2011 en Egipto sobre el camino electoral estuvo relacionada con las posibilidades reales de que el movimiento social asociado a las protestas tuviera un justo lugar en la carrera política. Un entrevistado me decía que él quería elecciones ya ante el riesgo de que los militares se quedaran con el poder y al mismo tiempo, que quería elecciones en dos o tres años para dar el compás de espera necesario que permitiera a los opositores crear organizaciones políticas competitivas, porque de otra manera solo podría ganar la oposición previamente organizada ${ }^{34}$. Esto efectivamente pasó (los Hermanos Musulmanes y los salafistas han ganado varias de las elecciones post-revueltas en Egipto). En otras palabras, más que un mérito propio, es un aprovechamiento de la debilidad de los movimientos sociales para competir como organización política en la arena electoral.

${ }^{33}$ Comunicado de los Comités de Coordinación Locales, 29 de agosto de 2011.

${ }^{34}$ Entrevista personal del autor con Gamal Eid (director ejecutivo de la Red Arábiga por la Información para los Derechos Humanos, basada en El Cairo) El Cairo, abril 2011. 
En Túnez, en unas elecciones a las que concurrieron más de 80 partidos políticos, el triunfo fue del partido An-Nahda (que significa Renacimiento) con $40 \%$ de los votos. En otras palabras, el triunfo en la calle había que validarlo con el triunfo en las urnas, lo que podría ser una trampa o una oportunidad, lo que dependía de la capacidad de pasar de la poética de la marcha a la política.

La posibilidad de dar el paso a la organización depende además, de una cultura política que lo permita, cuya construcción requiere de tiempo pero cuya necesidad para los opositores es inmediata. Por eso, allí donde los opositores habían ganado, el ritual de promulgar una nueva constitución fue bien recibido (Túnez) así como los esfuerzos por crear una nueva institucionalidad (Libia). La legitimidad de los nuevos gobiernos se ha buscado en procesos electorales y hasta en leyes previas a las revueltas. Lo electoral es más entendible, pero genera dudas la invocación de leyes pre-revolucionarias para responder a las preguntas del nuevo país con las estructuras del viejo, como si el viejo modelo de gobierno se hubiera agotado pero no su institucionalidad, lo que suena contradictorio.

La enseñanza en este caso tiene que ver con la falta de creatividad y el riesgo que exista a caer en el simple remplazo de una persona por otras sin tocar la forma de ejercicio de poder, sin crear una nueva cultura política y por tanto, no yendo más allá del ritual del aparente cambio de poder.

Sectores críticos del proceso árabe, cuya fase final lleva apenas tres años, exigen resultados inmediatos a pueblos que precisamente, se están estrenando en prácticas electorales más o menos abiertas (Túnez, Egipto y Libia), en conformación o fortalecimiento de su sociedad civil (Libia, Jordania, Bahréin, pero aplicable en general a todos los casos), en la creación de nuevas fuerzas políticas de orden nacional que enfrentan el poder previo (Libia, Siria), en la creación de mecanismos para limitar el uso de la fuerza por parte de las milicias que a su vez han sido necesarias en su lucha (Siria, Libia) y en la creación de alternativas políticas que sean capaces de rechazar y triunfar sobre partidos políticos de los poderes tradicionales (Túnez, Jordania, Yemen, Egipto), etc.

Es temprano aún para ofrecer resultados en un proceso inacabado. Fue necesario el paso del tiempo para medir las consecuencias de la caída del Muro de Berlín, del 11 de septiembre de 2001 y de la guerra de Irak. La tentación de pedir resultados en términos de la temporalidad de las personas puede llevar a sacrificar una mirada de medir resultados en términos de la historia de los pueblos.

Para algunos, un resultado es la caída del gobierno (Túnez, Egipto, Yemen, Libia), tener elecciones (Túnez, Egipto, Libia), o haber sido capaces de superar el miedo y alzarse contra el tirano (Siria, Bahréin). Para otros, no hay cambios sustanciales en la política económica que en el fondo sigue siendo dominada por una lógica neoliberal, la agenda de derechos humanos sigue siendo una asignatura pendiente y las banderas de género han sido desconocidas por completo. 
Ambos grupos tienen razón, pero ambos se equivocan al tener una mirada parcial. El problema es que la definición de revolución es cambiante; en las calles egipcias la palabra se usa con total convicción que la caída de Mubarak ya es una revolución; en Yemen por otro lado, el cambio de Saleh por su vicepresidente es una victoria algo menos que pírrica.

\section{El sujeto político: hacia un actor con agenda política}

Las miradas sobre la naturaleza de las revueltas árabes están permeadas de las miradas acumuladas sobre otros procesos de movilizaciones masivas de la sociedad en las calles. Debido a este sesgo, cada analista procura ver allí lo que resulta más familiar o peor aún, más conveniente a su propia agenda política.

A pesar de la proliferación de nuevas organizaciones políticas (movimientos sociales, partidos, coaliciones), por ejemplo en Túnez y en Egipto ${ }^{35}$, la organización necesita de conciencia política, hay que pasar 'de la poética a la política'. Como decía Marx, "creía vencer al enemigo con solo descartarlo mágicamente con la fantasía, y perdía toda la comprensión del presente ante la glorificación pasiva del futuro que le esperaba [...]” (Marx, 1995, p. 218). En este sentido la revuelta jordana se detuvo para dar pie a una reflexión más política y menos poética ${ }^{36}$.

Hay dos experiencias en la región que muestran las tensiones relacionadas con la unidad de acción entre agentes políticos con agendas compatibles pero en abierta competencia por el poder. La primera es la experiencia del nasserismo. Nasser llegó al poder en Egipto gracias al apoyo tanto de los Hermanos Musulmanes como de los marxistas, una vez consolidado en la dirección del ejército, persiguió a sus antiguos socios (Pommier, 2009, pp. 61-71).

La segunda es el caso de la revolución iraní de 1978-1979 en la que se repite el triángulo de nacionalistas, musulmanes y marxistas, pero en este caso es el Ayatolá Jomeini el que se instaura en el poder (Keddie, 2007, pp. 323-358). La dinámica política que se observa ahora en los países con procesos electorales es que no hay un único ganador, sino que la variedad de la calle pareciera empezar a reflejarse en el poder político, el problema es qué tanto y con qué poder real y hasta qué punto es eso posible ante la diversidad de agendas que las revueltas árabes muestran.

A pesar de todo eso, lo sucedido en términos de movilización social es mucho más que lo soñado por el más optimista y hasta los pasos concretos dados en el primer año

\footnotetext{
35 Para el caso de Egipto, ver las entrevistas personales con Gamal Eid (director ejecutivo de la Red Arábiga por la Información para los Derechos Humanos, basada en El Cairo) y Wael Navara (antiguo líder del Partido del Mañana -Hizd el-Ghad-, presidente de la Red de Partidos Liberales Árabes -NAL- y actual líder de la coalición "Iniciativa Egipcia"). El Cairo, abril y mayo de 2011. En De Currea-Lugo (2011).

${ }^{36}$ Entrevista con Nahed Hattar, intelectual jordano, Aman, mayo de 2011. En De Currea-Lugo (2011).
} 
son muy positivos para un periodo tan corto en un contexto tan difícil (cuatro presidentes fuera del poder, una Asamblea Constituyente en Túnez, elecciones en Egipto, etc.).

La conciencia de transformación es el motor del cambio, siendo el movimiento social solo el instrumento. ¿Qué nos demuestra la historia cuando la ausencia de organización política es reemplazada por la espontaneidad? El Bogotazo en Colombia, así como el Corralito argentino no llegaron a más, precisamente por la ausencia de un actor político organizado y determinante. Vale aclarar que nos referimos aquí al sujeto colectivo con voluntad de transformación de las relaciones de poder hacia formas más justas, excluyendo por tanto de esta definición a las élites y a otras fuerzas sociales que no busquen dichas transformaciones en medio de las revueltas actuales, por ejemplo, los militares egipcios ${ }^{37}$.

En el caso de las revueltas, la lista de protagonistas es tan extensa como sectores sociales y productivos tiene una sociedad: obreros de textiles en Egipto, tribus en Libia y Yemen, jóvenes de todos los países, comerciantes de Siria, campesinos de Yemen, mujeres en Arabia Saudita y en Egipto. Asimismo, gentes de Jordania, Bahréin, Sudán, Argelia y Marruecos se volcaron a las calles y sus agendas son tan disímiles como sus angustias vitales.

En tiempos pasados el actor político, identificado así por Marx, fue el movimiento obrero, definido como la vanguardia de la revolución. Hoy, el papel del movimiento obrero ha sido secundario -aunque no irrelevante (Barreñada, 2011 agosto) - y el liderazgo ha sido asumido por los movimientos sociales entre los que juegan un papel fundamental los jóvenes (alrededor del 50\% de la población es menor de 25 años). El movimiento obrero por sí solo no explica la revuelta (más determinante en Túnez pero marginal en Egipto), pero sin él no hubiera sido posible, se necesitó de la juventud ${ }^{38}$.

¿Pero la juventud -así en abstracto-, es un actor social? Muchos de ellos no dan el paso de la emoción de la acción a la teoría. Mientras los obreros tienen una relación definida con el modelo económico y con la forma de producción, mientras en él existe y se refleja la contradicción capital-trabajo, el ser joven per se no significa nada. Decir ‘jóvenes de todos los países uníos’ no sirve de mucho.

En todo caso, las penurias del obrero son compartidas en diferente medida por el árabe de hoy, especialmente si aceptamos que "el destino del obrero no es superado, sino extendido a todos los hombres" (Marx, 1844, p. 141) y por tanto, una mirada no ortodoxa nos permite encontrar una identidad del enajenado/explotado, así no tenga un carácter explícito como obrero.

\footnotetext{
${ }^{37}$ Aunque los militares no son necesariamente contrarios a los cambios, es el caso de Omar Torrijos en Panamá y de Gamal Nasser en Egipto con el Movimiento de Oficiales Libres de 1952, totalmente diferente a la lógica de los militares de Chile en 1973.

${ }^{38}$ Entrevista del autor con Nada Tarek El-Kouny, periodista de Ahram Online, enero de 2012.
} 
La pregunta por el sujeto político solo se puede responder por el momento, desde la heterogeneidad de los actores de las revueltas. Esa heterogeneidad no se niega diciendo que se marcha bajo banderas comunes (si las hubiera), pues la unidad de acción no significa necesariamente una unidad en el programa político.

Podríamos decir que lo común a los manifestantes es su identidad árabe (cualquier cosa que esto sea), pero la cultura árabe, con todas sus virtudes, podría ser estudiada también como un elemento que contribuye a la enajenación, como lo hace la religión, pues la enajenación no es un concepto exclusivo del capitalismo ni de lo económico ${ }^{39}$.

Un ejemplo de dicha enajenación, de dicha cultura política, es el machismo árabe que se expresa también en el mundo pre-islámico. Así puede darse una mezcla explosiva entre aspectos retardatarios de la cultura árabe y lecturas dogmáticas del Corán, con las medidas aplicadas por Gadafi tales como "la quema de instrumentos musicales en espacios públicos o la prohibición de cines, teatros o, en determinados periodos, las vestimentas occidentales y la enseñanza de idiomas 'imperialistas”, (Gutiérrez de Terán, 2011, p. 158).

Los argumentos contra una 'enajenación islámica' plantean que es posible, como lo formula Tariq Ramadán, un ‘humanismo musulmán’ que dé respuestas concretas a problemas concretos (citado en Roy, 2003, p. 108) y que modernizar el Islam no sería 'flexibilizar sus prescripciones' sino “inscribirse en una perspectiva de espiritualidad, de búsqueda de uno mismo, de desarrollo personal” (Roy, 2003, p. 112) en una lógica universal.

Los defensores de la cultura caen en la "principal trampa [de este concepto, que] está, como ya se vio, en considerar a las culturas entidades naturales, olvidando el proceso que llevó a determinarlas y a darles identidad" (Valdecantos, 1999, p. 94). Y ese proceso de construcción cultural no implica necesariamente que sus elementos sean transformadores o liberadores del ser humano.

Múltiples expresiones culturales podrían condicionar tanto al sujeto político como a su agenda. Por ejemplo, los patrones culturales machistas son contrarios a las reivindicaciones tanto de las mujeres egipcias como saudíes; la consolidación de una mirada tribal es contraria a los anhelos nacionalistas en Libia y Yemen, pues una suma de tribus no hacen una nación (eso lo saben los burgueses, para el caso de Yemen y de Libia); la noción de un Estado laico choca abiertamente con los grupos salafistas en Túnez, Siria y Egipto.

El nuevo sujeto político que surja de la 'calle árabe', debe leer con acierto las reivindicaciones árabes (sobre la libertad y la igualdad) y actuar en concordancia, trascendiendo las agendas mezquinas o distorsionadas en lógicas de la cultura y la religión para entonces ser en realidad, un sujeto de cambio. Su oportunismo político sería castigado, como lo fue en 2011 en los primeros gobiernos en Túnez, el gobierno militar provisional de Egipto

\footnotetext{
${ }^{39}$ Según Francisco Rubio Llorente (1974, pp. 40-41) la enajenación no es un asunto exclusivo ni del capitalismo ni de lo económico.
} 
que intentó quedarse con el poder y el corto gobierno de los Hermanos Musulmanes en Egipto, entre 2012 y 2013.

Ese nuevo actor no debe desconocer que, en una perspectiva revolucionaria a largo plazo, la contradicción capital-trabajo seguirá existiendo. Como decía Horkheimer, el cambio de otras contradicciones diferentes a las contradicciones de clase no lleva a la disolución de las clases (Horkheimer, 1983/1940). Un nuevo sujeto político no debería negar la existencia de clases sino que debería asumir en clave organizativa su complejidad (si pretende además, recoger las banderas del movimiento obrero).

Aunque algunos académicos siguen estudiando al ciudadano que vota, cada vez es más necesario tratar de entender al ciudadano que vive. Así, que la tarea del nuevo sujeto político es recuperar el espacio de la política, de la decisión colectiva, de la verdad social, hoy enmarañada en estadísticas de economistas neoliberales al servicio del capital. Ese sujeto político tiene que enfrentar el mito de que el mercado se mueve por fuerzas no-políticas, cuando la "desregulación, [la] flexibilización y [la] no intervención son las formas más agresivas de hacer política” (Martínez De Bringas, 2001, p. 39).

Ese sujeto político tendría que entender, lo ya citado: no basta ser gobierno sino que hay que tomar el poder. Decir: cambiar 'sin tomar el poder' es poética; pero tomar el poder sin cambiar es traición. No se trata de pedir prestado los instrumentos de poder por una temporada sino de transformar la sociedad, por eso el gran temor a que el cambio de nombres sin cambio en las relaciones de poder perpetúen viejos modelos con nuevas caras en Túnez, Libia, Egipto y Yemen.

Por eso en Túnez, Mohamed Ghanuchi, conocido como 'Monsieur Oui, Oui' (Señor sí, sí porque le daba la razón a Ben-Ali en todo), fue reemplazado rápidamente; y por esa misma razón en Egipto las marchas volvieron a la Plaza de la Liberación. Por eso los estudiantes de Yemen han rechazado la coalición de partidos políticos que se sumaron tarde a las revueltas, fueron funcionales al gobierno de Saleh y más que sus contradictores políticos, eran un poder igual esperando la hora del relevo, bajo el nombre de 'Encuentro Común'. En el marco de la unificación de Yemen del Norte y Yemen del Sur en un mismo país (1990) se abrieron nuevos espacios de participación política y de creación de movimientos sociales que fueron determinantes en las revueltas (Hamad, 2011, p. 90), mientras que la inexistencia de un proceso similar genera graves vacíos en el proceso de consolidación de un nuevo sistema para Libia.

Ese nuevo sujeto debe entender el costo político de apostar de una manera obtusa por lo local, no ya rescatando el sueño de la Nación Árabe ofrecida por Inglaterra durante la Primera Guerra Mundial, sino de plantear una 'Liga Árabe de los Pueblos' que permita avanzar no solo en la coyuntura actual sino en los cambios a futuro. Un sujeto político que entienda y asuma que, parafraseando a Horkheimer, quien no quiere hablar de capitalismo, no tiene derecho a hablar de democracia árabe (Horkheimer, 1983/1940). 
El Informe sobre el Desarrollo Humano Árabe de 2002 (UNDP, 2002) menciona las tres más grandes faltas de la región: inequidad de género, gobierno autoritario y restricciones al conocimiento (estos dos últimos también con sesgos de género). El mismo Informe de 2005 lo ratifica: "La sociedad árabe no reconoce el verdadero alcance de la participación femenina en las actividades económicas y sociales" (UNDP, 2005). El problema es si podemos llamar revoluciones democráticas a procesos que solo apuntan a uno de los tres problemas -el del gobierno autoritario- sin revisar su agenda patriarcal. Entonces, sin que la agenda de género tenga un puesto en las revueltas, es muy difícil hablar de revoluciones en el sentido que esta palabra tiene.

En este orden de ideas, el sujeto político debe reconocer, para ser realmente sujeto de cambio, el papel movilizador de las mujeres (sin desconocer con esta frase que ellas, de facto, ya son parte de ese sujeto político en proceso de configuración). En Egipto, cuando ellas decidieron hacer su propia 'marcha del millón de mujeres', el 8 de marzo de 2011, con sus reivindicaciones específicas, fueron rechazadas incluso por muchos de sus compañeros de revuelta. En Arabia Saudita, la principal reivindicación de las mujeres es que les permitan conducir. En Siria, el arresto masivo de hombres, casa a casa, fue respondido por marchas de mujeres que se organizaron para exigir la libertad de los detenidos.

En relación con los obreros, las revueltas árabes también han representado una oportunidad en dos sentidos: primero, desenmascarar el papel de los sindicatos oficialistas que inmovilizaban las protestas anti-neoliberales y segundo, proponer la creación y/o el fortalecimiento de sindicatos independientes (Barreñada, 2011). Su fuerza creciente se observa en la decisión del gobierno egipcio de transición que legisló prohibiendo las huelgas.

Hay que entender que esos sindicatos oficialistas jugaron un papel relevante en los movimientos nacionalistas e independentistas del pasado, "el problema esencial fue su falta de independencia, el sindicato fue el 'frente obrero' del partido oficial” (Barreñada, 2011). Ahora han florecido fuerzas sindicales independientes en la región.

Hay pues una necesidad de contar con un sujeto político y social capaz de liderar las revueltas árabes hacia buen puerto. Los movimientos sociales han jugado un papel movilizador, pero la calle no se ha visto necesariamente reflejada en las urnas ¿̇podrían los movimientos sociales mecánicamente convertirse entonces en partidos políticos? ¿Quétan real es la distinción entre partidos políticos y movimientos sociales en el mundo árabe? Hamas y Hizbollah son un ejemplo de mixtura entre movimiento social, partido político, organización armada y otras categorías tan presentes en los debates occidentales.

\section{Reflexión final}

Las agendas son claras: el neoliberalismo económico y la falta de apertura política. Para muchos de los líderes de las revueltas árabes, no se trata de cambiar un presidente sino una sociedad, en ese sentido serían revolucionarias, ya sean marchas pacíficas o lucha armada. 
El problema está en la indefinición de los escenarios, la temporalidad de los gobiernos, las transiciones políticas en curso. Dicho de otra manera, las personas piden resultados y consolidaciones a procesos históricos que toman su tiempo.

El proceso de las revueltas además se hace más temporal cuando aparecen figuras como la de gobiernos tutelados, democracias vigiladas, guardianes de la revolución (en referencia a los militares de Egipto, no a algunos jóvenes seguidores de Mao), vanguardias únicas e iluminados que tratan de decidir por encima y por fuera de los miles de manifestantes la suerte de los países árabes.

A pesar de lo anterior, las masas han seguido cuestionando gobiernos de transición hasta hacerlos renunciar (Túnez, Libia), construyendo una cultura política que obliga en su práctica a desarmar a milicias ya no necesarias para la causa (Libia), exigiendo castigo por los crímenes cometidos (Egipto, Yemen), evitando el secuestro de sus luchas y creando una nueva dinámica política en contextos donde la participación real de los movimientos sociales era impensable hace pocos años.

Hay muchas reivindicaciones de modernidad en las revueltas: elecciones, asambleas constituyentes, sindicatos de base, miradas de género, demandas de Estado social, juicios contra los antiguos líderes (Ben-Alí, Mubarak, Said El-Islam) e incluso cuestionamientos sobre la relación entre el Estado y la iglesia: dos tercios de la población encuestada en doce países manifiesta que se oponen a la interferencia clerical en la política (Arab Center For Research and Policy Studies, 2012). Si bien esta lista de elementos no es concluyente sobre el alcance y la dirección de las revueltas, sí es un indicativo.

Pero esa oleada de conceptos aparentemente modernos en la revuelta árabe, requiere de matices tal como indica Bernard Lewis (2000, pp. 7-8,17):

\footnotetext{
[...] palabras como 'democracia' o 'dictadura' constituyen préstamos o neologismos inventados para traducir términos occidentales; otras [palabras] como 'gobierno' o 'libertad' son palabras antiguas a las que se ha infundido nuevos significados [...] "nacionalidad y ciudadanía, nacionalismo y patriotismo son palabras nuevas en Oriente Medio, inventadas para nombrar los conceptos [...] La palabra ciudadano que deriva del concepto grecorromano de ciudad y quienes participan de ella, encarna una tradición política totalmente diferente y, por ello, semántica, para lo que no existe una terminología aproximadamente equivalente”.
}

Además de la transición política que se busca, hay un elemento clave que nace en la renuncia al miedo y es el hecho de crear otro tipo de cultura política: el 'orgullo de ser egipcio', la recuperación del rostro de Omar Al-Muktar (en Libia), la acción de ganar la calle, el debate político por días y días en plazas públicas (en países donde el silencio era la norma), significa la construcción de un ciudadano árabe crítico, deliberativo y movilizado. Recordemos el papel de los jóvenes, su actitud desafiante al poder existente 
y prevaleciente (padres, policía, religión, Estado, etc.) es uno de los principales responsables de dicha nueva cultura política.

Pero esa nueva agenda política y social se suma (no remplaza) a viejos asuntos pendientes del movimiento social árabe: la ocupación de Palestina, la descolonización del Sahara, el genocidio de Darfur, la Guerra Fría de Oriente Medio (entre Arabia Saudita e Irán) que se extiende de Irak a Siria y que busca un espacio en la crisis de Bahréin, etc.

La idea de 'ciudadanía árabe' (de contar con un sujeto miembro de una comunidad política), se fortalece no en lo individual sino en lo colectivo; ayudan a dicho fortalecimiento lo musulmán pues la solidaridad está en la base de dicha religión (el zakat) y se observa en prácticas concretas (Los Hermanos Musulmanes, Hamas, Hizbollah).

Lo que se observa en la fase posterior a la caída de los gobiernos es que las masas continúan en las calles, han tumbado incluso gobiernos de transición (Túnez), presionado decisiones de los nuevos parlamentos (Libia), evitado el secuestro del proceso por parte de militares y/o de los Hermanos Musulmanes (Egipto) y mantenido la llama de la protesta a pesar de serios reveses, como sucede en los casos todavía no triunfantes de Yemen, Jordania y Bahréin. No es el caso de las revoluciones en las que finalmente el mando militar se hace con el poder político (Nicaragua, Cuba) sino que la movilización social actúa (a pesar de sus limitaciones) como un garante de los cambios y un supervisor del nuevo gobierno.

Los movimientos sociales son los que dotan de fuerza política al sujeto social arabomusulmán en la coyuntura actual. Pero no todas las revoluciones, ni todos los sujetos de la actualidad luchan contra la enajenación, de hecho la revolución de Gadafi en 1969 la aumentó y algunas de las fuerzas políticas que se mueven hacia la implantación de regímenes teocráticos (salafistas de Túnez, extremistas de Siria) o propuestas de viaje al pasado (militares de Egipto), van en la misma dirección.

Hay una brecha entre la vieja izquierda y los movimientos sociales árabes de nuevo cuño. Un sector de la izquierdista ve a los rebeldes en armas de Libia y de Siria como terroristas y a Gadafi y a Al Asad como las nuevas víctimas del imperialismo de Occidente. También Hungría en 1951 y Checoslovaquia en 1968 trataron de ser explicadas con la ‘teoría del complot', mientras se 'justificó' la ocupación de Afganistán. Así, la acción internacional se juzga de ‘solidaridad' o ‘injerencia' según convenga.

Las revueltas -hasta ahora- parecen apuntar a ser más revoluciones burguesas que acercan el mundo árabe a la modernidad y apuntan al desarrollo capitalista (con Estado social), al tiempo que conjugan su naturaleza religiosa hacia un modelo más cercano al islamismo moderado de Turquía que al radical de Irán. Pero la posibilidad de trascender un marco de modernidad burguesa, liberalismo político y conservadurismo religioso, está por verse. Tal alcance no depende solo de los movimientos sociales árabes sino de los contrapoderes al interior de cada uno de los países. 
La proyección regional se da en la sucesión de eventos país-a-país, pero no en agendas que trasciendan la lógica del Estado-nación (hasta la solidaridad armada en Libia y Siria se lee en el marco de naciones). Dichos marcos nacionales y/o religiosos, podrían ser la negación misma de las reivindicaciones árabes. Las barreras nacionalistas y religiosas enajenarían la lucha inicial.

Los movimientos sociales, líderes de las revueltas, tratan de ir más allá de ese paradigma, pero no terminan de tener claro su paradigma alternativo. El papel de los movimientos sociales - real y simbólico- enfrenta en todo caso graves problemas: su falta de unidad en torno a una agenda mínima, su naturaleza que le impide reconocer las (en todo caso existentes) contradicciones de clase y su falta de organización política. Y así, el riesgo de la dispersión y la eventual incapacidad de dar el paso de lo poético a lo político están sobre la mesa.

Estando en El Cairo en abril de 2011, pregunté a un experimentado trabajador egipcio de derechos humanos sobre el futuro, esperando oír algunas teorías. A pesar de que el entrevistado había estado participando asiduamente en toda la revuelta, su respuesta me dio una lección de prudencia, pues cuando le pregunté “¿Qué está pasando y qué va a pasar?, me contestó: "nadie lo sabe" 40 . A pesar de que nadie lo sepa, lo que sí sabemos es que ya los movimientos sociales árabes dejaron espacios de enseñanza política que no debemos menospreciar y que debemos explorar más allá del impacto mediático. Cuando se aplaque el humo de la fiesta, veremos entonces con mejores ojos los procesos organizativos hoy ocultos que tendrán entonces aún más cosas por enseñarnos.

\section{Referencias}

Atuán, A. (2011, marzo 7). Arabia Saudí y la fetua de los predicadores de los sultanes. Al-Fanar. Disponible en: http://www.boletin.org/control/product / product_id=QU-0907-03-11.

Al Anani, K. (2012). La religión en la era posrevolucionaria, Afkar, Ideas 32. Disponible en: http://www.afkar-ideas.com/article/?id=4774.

Al Khamissi, K. (2009). Taxi. Madrid: Almuzara

Alba Rico, S. (2011, febrero). Túnez, ¿Una revolución inesperada?, Diagonal. Disponible en: https://www.diagonalperiodico.net/global/tunez-revolucion-inesperada.html.

Álvarez-Ossorio, I. (2008, julio-agosto). El movimiento islamista en Siria, Política Exterior, (124), 83-94.

\footnotetext{
${ }^{40}$ Entrevista personal del autor con Gamal Eid (director ejecutivo de la Red Arábiga por la Información para los Derechos Humanos, basada en El Cairo) El Cairo, abril 2011.
} 
Álvarez-Ossorio, I. (2009). Siria contemporánea. Madrid: Síntesis

Álvarez-Ossorio, I. y Gutiérrez De Terán, I. (2011). Informe sobre las Revueltas Árabes. Madrid: Ediciones del Oriente y del Mediterráneo.

Álvarez-Ossorio, I. y Zaccara, L. (Ed.) (2009). Elecciones sin elección. Madrid: Ediciones de Oriente y del Mediterráneo.

Alvarez-Ossorio, I. (Ed.) (2013). Sociedad civil y contestación en oriente medio y norte de África. Barcelona: CIDOB.

Arab Center For Research And Policy Studies. (2012). Measurement of Arab Public Opinion Project. Arab Opinion Index 2011. Doha, Qatar. Disponible en: http:// english.dohainstitute.org/file/get/15e538f7-ab57-48c7-b576-a1046d8434ed.pdf

Arab Fund for Economic and Social Development (2005).

Barreñada, I. (2011). Las revoluciones árabes, la cuestión de la justicia social y el papel los sindicatos. Hoja de Ruta, Redes Sociales, (37). Disponible en: http://www. hojaderuta.org/pdf.php?id_texto $=655 \& i d \_r e v i s t a=50$

Barreñada, I. (2012). El continuum contestatario en los países árabes: movimientos sociales, sociedad civil y ciudadanía. Regions \& Cohesion, 2(3), 45-66

Chomsky, Noam. (2011, febrero 4). Arab Revolutions: It's not Radical Islam that worries the US - it's Independence. The Guardian. Disponible en: http:// www.theguardian.com/commentisfree/cifamerica/2011/feb/o4/radical-islam -united-states-independence?CMP=twt_gu.

Clashes erupt around Cairo's Tahrir Square. (2011, marzo 9). Al Jazeera. Disponible en: http://www.aljazeera.com/news/middleeast/2011/o3/201139175317866295.html.

Corm, G. (2009). Historia de Oriente Medio. Barcelona: Península.

De Currea-Lugo, V. (2011) Las revueltas árabes: notas de viaje. Bogotá, Le Monde Diplomatique.

De Currea-Lugo, V. (2012, invierno). Questioning 'mono-causal' perceptions of the Arab revolts. Regions Cohesion, 2(3), 67-83.

De Currea-Lugo, V. (2013, septiembre 18). Bahréin es un negocio familiar, no un país. El Espectador. Disponible en: http://www.elespectador.com/noticias/elmundo/ barein-un-negocio-familiar-no-un-pais-articulo-447055.

De Currea-Lugo, V. (2013, octubre 17). El prisma de la rebelión. El Espectador. Disponible en: http://www.elespectador.com/noticias/elmundo/el-prisma -de-rebelion-articulo-452762. 
Espinosa, Á. (2011, febrero 19). El Ejército libio abre fuego para sofocar las revueltas El País. Disponible en: http://internacional.elpais.com/internacional/2011/02/19/ actualidad/1298070004_850215.html

El-Kouny, N. (2011, diciembre 6). Islamists add obstacles to gender equality, but no reason to panic: Women activists. Ahram Online. Disponible en:http://english. ahram.org.eg/NewsContent/33/100/28525/Elections-/News/Islamists-addobstacles-to-gender-equality,-but-no.aspx

Engels, F. (1895). Introducción. En Marx, K. Las luchas de clases en Francia de 1848 a 185o. Berlín: Progreso

Fauad, W. (2010). Facebook y la Juventud árabe: ¿aactivismo social o liberación cultural? Awraq, (2), 93-101

Fligstein, N. y Mcadam, D. (2011). Toward a general theory of Strategic Action Fields. Sociological Theory, 29(1), 1-26.

Fuensanta, J., Lorca, A. y James, A. (2011). Tribus, Arma y Petróleo. Garnada: Algon.

Gutiérrez de Terán, I. (2011). La revuelta libia y las incógnitas de la transición, En Alvarez-Ossorio, I. y Gutiérrez De Terán, I. (Eds.). Informe sobre las Revueltas Árabes (pp. 147-180)., Madrid: Ediciones del Oriente y del Mediterráneo.

Hamad Zahonero, L. (2011). Yemen: de la revolución pacífica a las luchas por el poder. En Alvarez-Ossorio, I. y Gutierrez De Terán, I. (Eds.). Informe sobre las Revueltas Árabes (pp. 87-116), Madrid: Ediciones del Oriente y del Mediterráneo.

Highlights of Gaddafi son's address (2011, febrero 21). Al Jazeera. Disponible en:http:// www.aljazeera.com/news/africa/2011/o2/201122111127102872.html

Horkheimer, M. (1983/1940). El Estado autoritario. (1983). Bogotá: Argumentos.

Hughes, J. (2007). Chechnya: from Nationalism to Jihad. Philadelphia: University of Pennsylvania Press.

Human Rights Council. (2011, junio 1). Report of the International Commission of Inquiry to investigate all alleged violations of international human rights law in the Libyan Arab Jamahiriya. Disponible en: http://www.ohchr.org/Documents/ HRBodies/HRCouncil/RegularSession/Session19/A.HRC.19.68.pdf

Human Rights Watch. (2011, febrero 18). Libya: Security Forces Kill 84 Over Three Days. Disponible en: http://www.hrw.org/news/2011/02/18/ libya-security-forces-kill-84-over-three-days

Keddie, N. (2007). El Irán Moderno. Barcelona: Belacqua. 
Kiali, M. (2011, abril 5). Interrogantes sobre el estado revolucionario de las sociedades árabes. Al-Fanar. Disponible en: http://www.boletin.org/control/ product/ product_id=HY-1005-04-11

Kodmani, B. y Legrand, F. (2013, septiembre). Arab Reform Initiative: Empowering the Democratic Resistance in Syria, Beirut-Paris,

Lampridi-Kemou, A. (2011). Egipto: la revolución inconclusa. En Alvarez-Ossorio, I. y Gutierrez De Terán, I. (Eds.) Informe sobre las Revueltas Árabes, Madrid: Ediciones del Oriente y del Mediterráneo. pp. 59-86

Lewis, B. (2000). Las identidades múltiples de Oriente Medio. Madrid: Siglo XXI.

Libya revolt spreads to Tripoli. (2011, febrero 21). Al Jazeera. Disponible en: http:// www.aljazeera.com/news/africa/2011/o2/201122131439291589.html

Mansfield, P. (2003). A history of the Middle East. London: Penguin.

Martínez de Bringas, A. (2002).Globalización y derechos humanos. Bilbao: Universidad de Deusto.

Martínez, G. (2011). El proceso revolucionario tunecino: tiempos, contextos y actores, En Alvarez-Ossorio, I. y Gutiérrez De Terán, I. (Eds.) Informe sobre las Revueltas Árabes (pp. 27-58), Madrid: Ediciones del Oriente y del Mediterráneo.

Marx, K. (1844). Sobre la cuestión judía. Buenos Aires: Promoteo.

Marx, K. (1974). Primer manuscrito. Manuscritos. Economía y filosofía (quinta edición). Madrid: Alianza Editorial.

Marx, K. (1984). Contribución a la Crítica de la Filosofía del Derecho de Hegel. Buenos Aires: Ediciones El Signo.

Marx, K. (1995). Las luchas de clases en Francia de 1848 a 1850. El dieciocho brumario de Luis Bonaparte. Madrid: Espasa Calpe.

Moghul, H. (2011, marzo 18). This isn't 1989, Institute for Social Policy and Understanding. Disponible en: http://ispu.org/GetArticles/48/2062/Publications.aspx

Mubarak swears in new cabinet. (2011, enero 31). Al Jazeera. Disponible en: http:// www.aljazeera.com/news/middleeast/2011/o1/2011131132324475241.html

Pasquino, G. (1983). Movimientos sociales. En Bobbio, N. et al. Diccionario de Política, (pp. 1015-1019). Disponible en: http://www.ps-santafe.org/admin/upload/d2/ ApuntesdelDiccionariodePoltica.pdf

Pommier, S. (2009). Egipto: Las cadenas de Prometeo. Barcelona: Bellaterra. 
Roy, O. (2003). El Islam mundializado. Barcelona: Bellaterra

Rubio Llorente, F. (1974). Introducción. En Marx, K. Manuscritos (pp. 40-41). Madrid: Alianza Editorial.

Sharián, D. (2011, marzo 3). ¿̇Revoluciones o “conspiración?. Al Hayat. Disponible en: http://www.boletin.org/boletinarticulo.pdf?product_id=HY-0902-03-11

Tarrow, S. (2004). El poder en movimiento. Los movimientos sociales, la acción colectiva y la política. Madrid: Alianza.

The World Bank (2009). The Status \& Progress of Women in the Middle East \& North Africa. Disponible en: http://siteresources.worldbank.org/INTMENA/Resources/MENA_Gender_Compendium-2009-1.pdf

UNDP (2005). Arab Fund for Economic and Social Development: Arab Human Development Report 2005: Towards the Rise of Women in the Arab World. New York: UNDP.

UNDP (2002). Arab Fund for Economic and Social Development: Arab Human Development Report 2002: Creating Opportunities for Future Generations. New York: UNDP.

Valdecantos, A. (1999). Contra el relativismo. Madrid: Visor.

Whitehead, A. (2011, diciembre 23). "It reminds me of 1848...” Entrevista con Eric Hobsbawn. BBC News Magazine. Disponible en: http://www.bbc.com/news/ magazine-16217726

Yalman, N. (2011, abril-junio). La caída de Mubarak. Egipto y más allá. Vanguardia Dossier, (39), 79-87. 